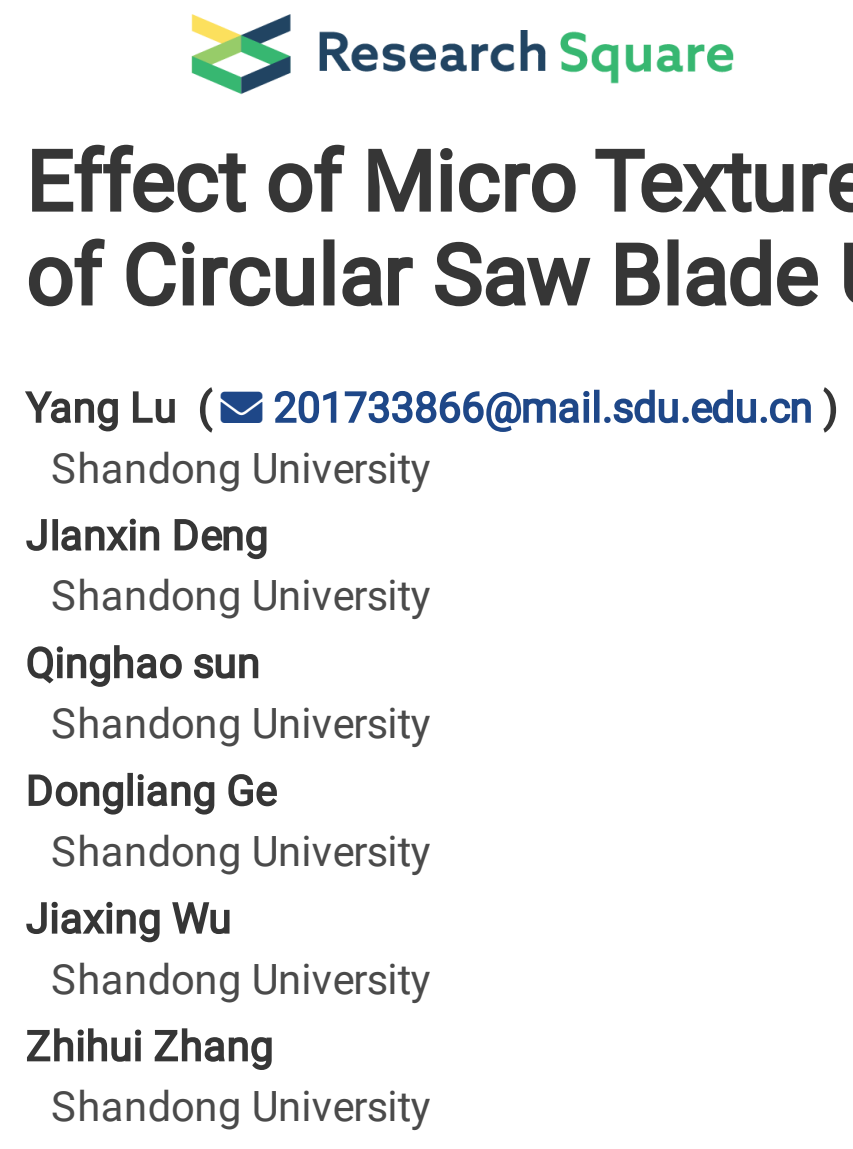

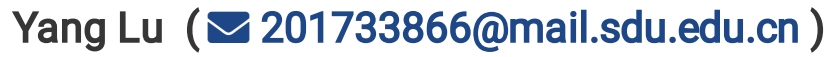 \\ Shandong University \\ Jlanxin Deng \\ Shandong University \\ Qinghao sun \\ Shandong University \\ Dongliang Ge \\ Shandong University \\ Jiaxing Wu \\ Shandong University \\ Zhihui Zhang \\ Shandong University
}

\title{
Effect of Micro Textures on the Cutting Performance of Circular Saw Blade Under Fluid Lubrication
}

\section{Research Article}

Keywords: micro textures, circular saw blade, cutting performance, cutting fluids

Posted Date: February 12th, 2021

DOl: https://doi.org/10.21203/rs.3.rs-201377/v1

License: (c) (1) This work is licensed under a Creative Commons Attribution 4.0 International License.

Read Full License 


\title{
Effect of micro textures on the cutting performance of circular saw blade under fluid lubrication
}

\author{
Yang Lu, Jianxin Deng ${ }^{*}$, Qinghao Sun, Dongliang Ge, Jiaxing Wu, Zhihui Zhang \\ Key Laboratory of High Efficiency and Clean Mechanical Manufacture of MOE, School of Mechanical \\ Engineering, Shandong University, Jinan 250061, China \\ * Corresponding author. \\ Tel.: +8653188399769. \\ E-mail address: jxdeng@sdu.edu.cn (Jianxin Deng).
}




\begin{abstract}
:
In this paper, linear micro textures that parallel to the sawtooth edge were fabricated on the surface of the high speed steel W6Mo5Cr4V2 circular saw blade by laser engraving. Further, cutting performance of micro textured circular saw blade (TCS) and traditional circular saw blade (CS), including sawing arc length, sawing force, sawing temperature, machined surface roughness and wear mechanism, were investigated in sawing 304 stainless steel pipes under the cutting fluid condition. Results showed that the largest sawing arc length and sawing force were occurred on the circular saw blade sawing outward from the inner wall. In addition, TCS circular saw blade exhibited better cutting performance and the mechanisms were found, on the one hand, the effective sawtooth-chip contact length was reduced due to the micro textures fabricated on the sawtooth surface, on the other hand, cutting fluid can be better penetrated into the micro textures and formed stable lubrication film in sawtooth-chip contact interface.
\end{abstract}

Keywords: micro textures; circular saw blade; cutting performance; cutting fluids 


\section{Introduction}

In the manufacturing industry, sawing as the starting point of workpiece machining had become one of the important process in the manufacturing. Cutting tools employed in the sawing process was specially, which was characterized by a certain arrangement of the sawtooth fabricated on the cutting edge of the tools. It can be classified into three kinds according to the application and structure of saw blade, which were hack saw blade [1], band saw blade [2, 3], and circular saw blade [4, 5]. The circular saw blade was widely used in the cutting of various kinds of metal and wood due to the higher machining accuracy and cutting efficiency in comparison with the band saw blade sand hack saw blade. According to the material and parameters of the sawtooth, the circular saw blade can be divided into two categories, one was that the solid saw composed of high speed steel or cemented carbide; the other was that the sawtooth with good hardness and wear resistance inserted or welded into the circular saw blade[6]. The cutting performance, wear characteristic and dynamic stability of the circular saw blade were investigated by numerous scholars [7-11]. Bradbury et al. [7] employed M2 high speed steel as circular saw blade material sawing difficult-to-cut material, and indicated that the sawing characteristic of the workpiece and tools material play a significant role in the sawing process. Alam et al. [10] presented a method to improve the stability of the circular saw blade by controlling workpiece feed speed, and monitored the lateral deflection of the saw blade. It indicated that the lateral deflection of circular saw blade within a desired limit.

Recently, many scholars had proved that micro textures were an effectively method to improve the friction condition of the friction pair surface, and micro textures were widely used in piston rings, tools, seals, wet clutches, and bearings surface [12-18]. Different types of micro textures engraved on the surfaces of the cutting tools have shown the effect in lowering sliding friction, reducing tool-chip contact length, promoting heat dissipation and relieving adhesive wear [19-23]. Kawasegi et al. [23] fabricated three types of patterns (parallel, perpendicular and cross patterns) on the rake face of the cutting tools. It 
was found that the textures perpendicular to the chip flow was beneficial to reduce cutting force. Deng et al. [24] produced three rake-face textured tools with different micro structures and found that the elliptical grooves promoted better dry cutting performance than the parallel or linear grooves. In addition, micro textures also used in drilling and milling process[25-28]. Zhou et al. [27] successfully fabricated micro textures parallel to the cutting edge on the rake face of the milling tools and carry out milling tests with nano-fluids, it obtained that the cutting force, surface roughness and wear rate of the tools were significantly decreased. Ling et al. [28] fabricated rectangular micro textures on the surface of drill tools, and found that the micro textures effectively reduced the adhesion of the workpiece material and improved the tools life. However, very limited research works have been reported concerning micro textures fabricated on the sawtooth surface of the circular saw blade. Thus, the effect of micro textures on the cutting performance of circular saw blade needed to be further studied.

In this paper, four linear micro textures that parallel to the sawtooth edge were fabricated on the surface of the high speed steel W6Mo5Cr4V2 circular saw blade by laser engraving. Then, the depth, width and microstructure of the micro textures were obtained. Sawing 304 stainless steel pipes tests were carried out with the micro textured circular saw blade (TCS) under the cutting fluid condition. The sawing properties, including sawing arc length, sawing forces, sawing temperatures, machined surface roughness and wear of the tools were investigated. This research can provide a good reference for reducing the wear of circular saw blade, improving the machining surface quality and prolonging the tools life. If possible, micro textured circular saw blade will be widely applied industrially in the future.

\section{Experimental details}

\subsection{Specimen preparation}

In this paper, High speed steel W6Mo5Cr4V2 was chosen as circular saw blade material from 
Yongkang Meili Juye Co., Ltd., China, the composition and mechanical properties of circular saw blade were shown in Table 1, As shown in Fig. 1, the diameter of circular saw blade was $200 \mathrm{~mm}$, thickness was $2 \mathrm{~mm}$, teeth were 150 , teeth space was $4.2 \mathrm{~mm}$, and the installation hole diameter was $32 \mathrm{~mm}$. Before micro texturing, in order to removed surface dirt, the circular saw blade was put in the alcohol solution ultrasonic cleaning for $15 \mathrm{~min}$, and then drying for $10 \mathrm{~min}$. The micro textures were designed and fabricated on the rake face by Nd: YAG laser equipment (DP-H50, Jinan Xinchu Co., Ltd.,China) and the processing parameters were listed in Table 2. The circular saw blade was fixed on the indexing plate, rotated the indexing by $2.4^{\circ}$ degrees after each machining until all the teeth were micro textured. The micro textures of the teeth surface were observed using white light interferometer (Wyko NT9300, Veeco Inc., USA) and scanning electron microscope (SEM; QUANTA FEG 250, FEI Inc., USA).

Table 1. Composition and mechanical properties of circular saw blade.

\begin{tabular}{rcccccccccc}
\hline Material & C & W & Mo & Cr & V & Mn & Fe & Density & Hardness & $\begin{array}{c}\text { Young's } \\
\text { modulus }\end{array}$ \\
\hline W6Mo5 & 0.91 & 6.05 & 5.30 & 4.15 & 1.95 & 0.35 & Bal & $8.3 \mathrm{~g} / \mathrm{cm}^{3}$ & $12.6 \mathrm{GPa}$ & $204 \mathrm{GPa}$ \\
Cr4V2 & wt. $\%$ & wt. $\%$ & wt. $\%$ & wt. $\%$ & wt. $\%$ & wt. $\%$ & & & & \\
\hline
\end{tabular}

Table 2. Experimental parameters of the Nd:YAG laser.

\begin{tabular}{cccccc}
\hline Wavelength (nm) & Power(W) & Frequency $(\mathbf{K H z})$ & $\begin{array}{c}\text { Scanning speed } \\
(\mathbf{m m} / \mathbf{s})\end{array}$ & $\begin{array}{c}\text { Number of } \\
\text { scan }\end{array}$ & $\begin{array}{c}\text { Pulse duration } \\
(\mathbf{n s})\end{array}$ \\
\hline 1064 & 12 & 20 & 150 & 1 & 10 \\
\hline
\end{tabular}

Fig. 2 illustrated the schematic diagram and SEM surface morphologies of the micro textures. As shown in this figure, four micro textures were designed in the sawtooth surface, and the distance from the cutting edge was $200 \mu \mathrm{m}$, the spacing between the micro textures was $300 \mu \mathrm{m}$. The three-dimensional surface profile and cross section morphology of micro textures were shown in Fig. 3. It can be seen that the depth of the micro textures was about $10 \mu \mathrm{m}$, width was about $45 \mu \mathrm{m}$. 

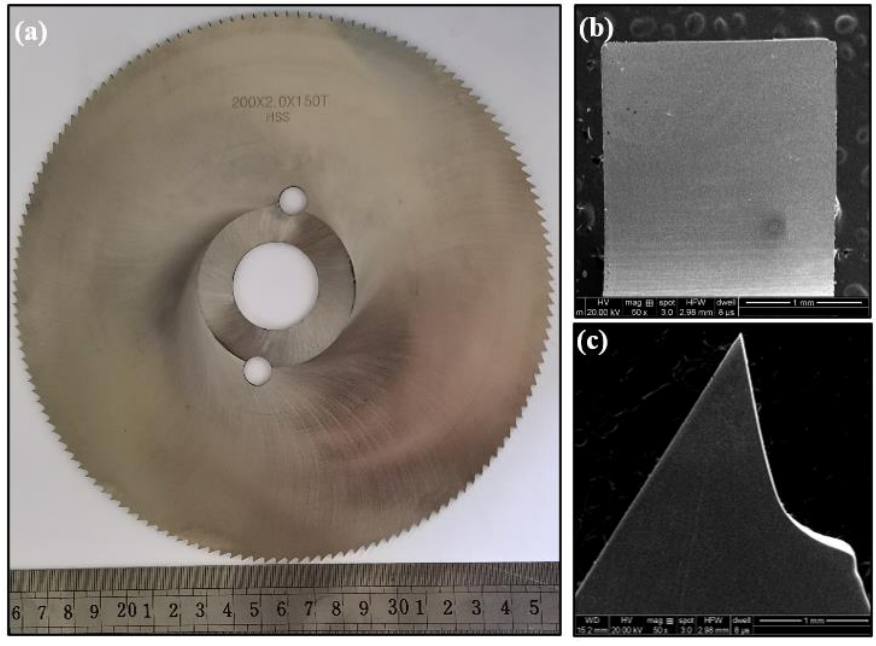

Fig. 1 The photographs and SEM micrographs of a circular saw blade: (a) photographs of circular saw blade;

(b) rake face of the sawtooth; (c) side morphology of the sawtooth.
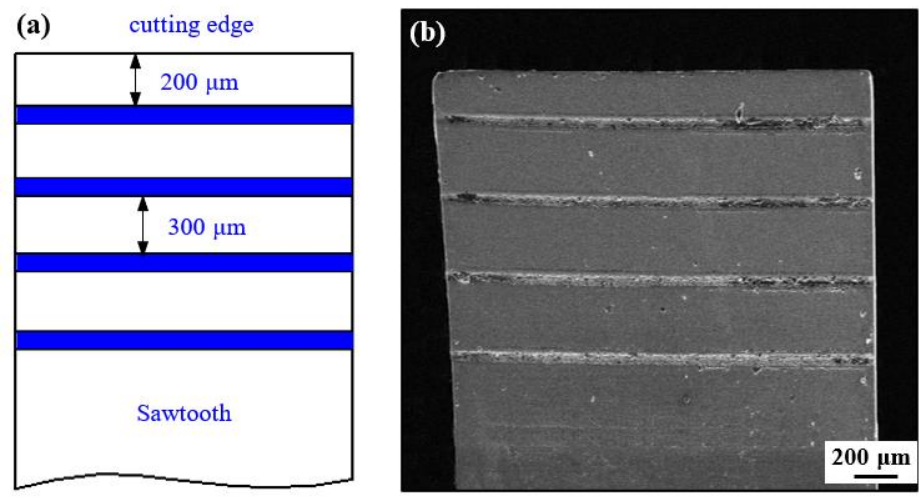

Fig. 2 The sawtooth with micro textures: (a) Schematic diagram of the rake face micro textures; (b) SEM image of textured surface.
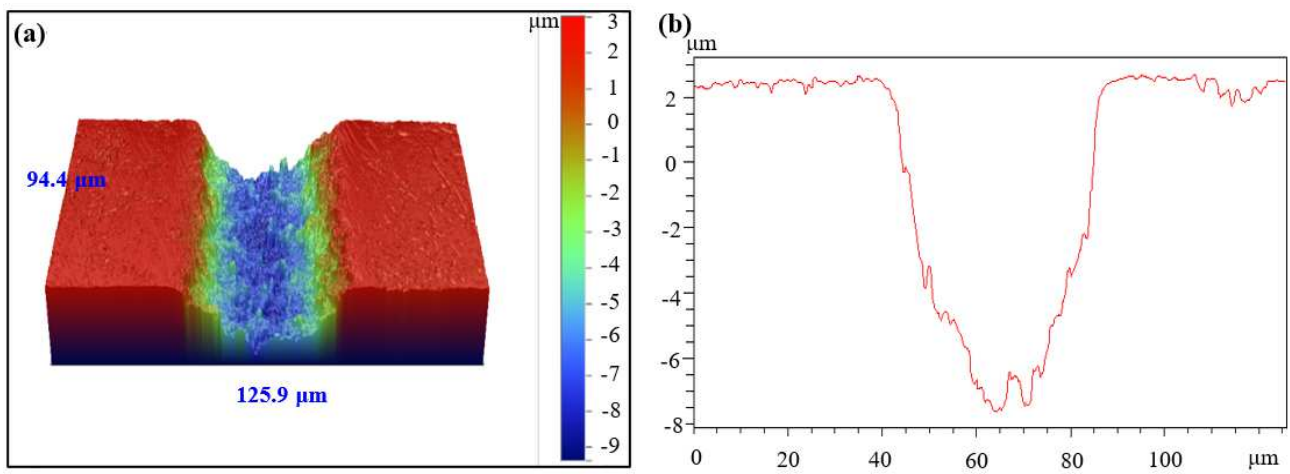

Fig. 3 Surface morphology and geometry of the texture: (a) 3D optical micrographs of one micro-groove; (b) section profile of the micro-groove. 


\subsection{Sawing tests}

Fig. 4 showed the photos of sawing tests that executed with turning machine $\mathrm{CKD} 6150 \mathrm{H}$. The circular saw blade was mounted on the spindle of the machine tool and with the following geometry: rake angle $\gamma=$ $-15^{\circ}$, sawing width $d=2 \mathrm{~mm}$. Two kinds of circular saw blade were prepared: the micro textured was fabricated on the rake face of the sawtooth (named TCS), and the conventional circular saw blade with the same composition was also employed (named CS) for the purpose of comparison. The 304 stainless steel pipes were employed as the workpiece material with the diameter of $30 \mathrm{~mm}$ and the wall thickness of $2 \mathrm{~mm}$. The 304 stainless steel pipes were installed and fixed on the tool rest and fed along the Y-axis at a certain rate. The entire process of TCS and CS circular saw blades sawing tests were under the emulsified cutting fluids (solcut oil-V600, DOMINO Co., Ltd., China) and the sawing conditions were shown in Table 3.

Table 3. Some parameters of the sawing tests.

\begin{tabular}{ll}
\hline Feed rate (f) & $0.4,0.6,0.8,1.0,1.2 \mathrm{~mm} / \mathrm{r}$ \\
Cutting speed (v) & $50,100,150 \mathrm{~m} / \mathrm{mim}$ \\
Workpiece & 304 stainless steel pipe \\
Cutting tool & High speed steel W6Mo5Cr4V2 \\
Sawing machine & CKD6150H \\
\hline
\end{tabular}

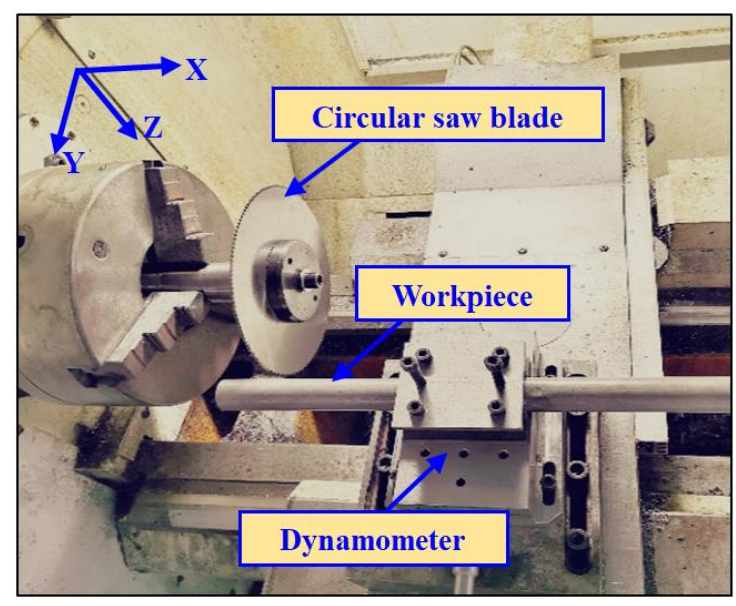

Fig. 4 The photos of sawing 304 steel pipes tests. 
The sawing forces were recorded by piezoelectric dynamometer Kistler 9275A. The sawing temperature was measured by an infrared thermal imager (Fotric 225/226) when the circular saw blade sawing 304 stainless steel pipes. The surface and side worn morphologies of sawtooth were investigated by scanning electron microscope (SEM; QUANTA FEG 250, FEI Inc., USA), energy-dispersive X-ray spectroscope (EDS, QUANTA FEG 250, FEI Inc., USA) and optical microscope (VK-X200, KEYENCE Co., Ltd., China). In addition, the measurement of the average machined surface roughness Ra was conducted at three different locations by a roughness tester (TR200, JITAIKEYI Inc., China).

\section{Results and discussion}

\subsection{Sawing arc length}

The schematic diagram of sawing force was showed in Fig. 5 (a). In this work, the sawing force was affected by the sawing force per tooth, sawing arc length and teeth space. The sawing force $F$ and sawing arc length $L$ were obtained from the following equations:

$$
\begin{aligned}
& F=\frac{P g L}{t} \\
& L=\left\{\begin{array}{lc}
\frac{\pi R_{1} \arcsin \left(x / 2 R_{1}\right)}{90} & (0<\lambda<m, \text { or } 2 R-m<\lambda<2 R) \\
\frac{\pi R_{1}\left\{\arcsin \left(x / 2 R_{1}\right)-\arcsin \left(x_{1} / 2 R_{1}\right)\right\}}{90} & (m<\lambda<2 R-m)
\end{array}\right. \\
& x=2 \frac{\sqrt{\left(R_{1}+R-\lambda / 2\right) \mathrm{g}\left(R_{1}-\lambda / 2\right) \mathrm{g}(R-\lambda / 2) \mathrm{g} \lambda / 2}}{R_{1}+R-\lambda} \quad(0<\lambda<2 R) \\
& x_{1}=2 \frac{\sqrt{\left(R_{1}+r-\lambda / 2\right) \mathrm{g}\left(R_{1}-\lambda / 2\right) \mathrm{g}(r-\lambda / 2) \mathrm{g} \lambda / 2}}{R_{1}+r-\lambda} \quad(m<\lambda<2 R-m)
\end{aligned}
$$

Where sawing force $F$ was the sum of main force $F z$ and radial thrust force $F y, P$ was the sawing force per tooth, $L$ was sawing arc length, and $t$ was the teeth space, $R_{l}$ was the diameter of circular saw blade, $R$ was external diameter of the workpiece, $r$ was inside diameter of the workpiece, $m$ was wall thickness, $\lambda$ was the sawing depth. 
In the sawing process, the teeth space $t$ and the sawing force of each tooth $P$ were constant, so the sawing force was proportional to the sawing arc length. The variation of sawing arc length was showed in Fig. 5 (b). When the sawing depth increased from 0 to $2 \mathrm{~mm}$, the sawing arc length was increased rapidly, from 0 to about $14 \mathrm{~mm}$. Then, the sawing arc length began to decrease and remain stably about $4 \mathrm{~mm}$ with the increasing of sawing depth. Subsequently, the sawing arc length began to increase again, and the sawing arc length reached the maximum at the sawing depth of $28 \mathrm{~mm}$, which was about $16 \mathrm{~mm}$. Finally, the sawing arc length rapidly decreased to $0 \mathrm{~mm}$.
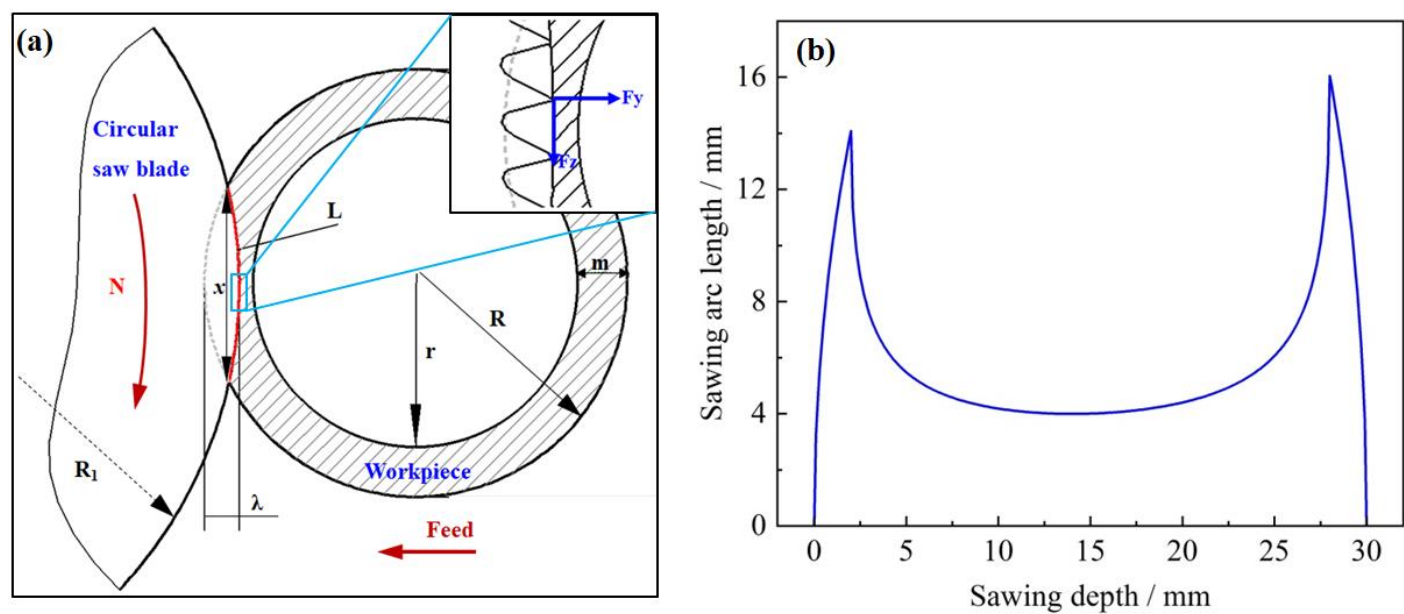

Fig. 5 The schematic diagram of sawing force and variation of sawing arc length: (a) schematic diagram; (b) sawing arc length.

\subsection{Sawing force}

The effect of the sawing speed and feed rate on the sawing force (main force $F z$, and radial thrust force Fy) for TCS and CS circular saw blade were analyzed. Fig. 6 illustrated the variation of sawing force at sawing speed $50 \mathrm{~m} / \mathrm{min}$ and feed rate $0.8 \mathrm{~mm} / \mathrm{r}$. For CS circular saw blade, the variation of main force $F_{z}$ was increased sharply from 0 to about $270 \mathrm{~N}$ before $2 \mathrm{~s}$. Then $F z$ decreased quickly and reached the minimum value about $95 \mathrm{~N}$ at $8 \mathrm{~s}$. Afterwards, $F z$ began to increased and reached the maximum value 
about $290 \mathrm{~N}$ at $14.5 \mathrm{~s}$. Finally, $F z$ decreased sharply from 290 to $0 \mathrm{~N}$. The variation trend of radial thrust force $F y$ was consistent with that of $F z$, and the maximum and minimum values were about $190 \mathrm{~N}$ and $55 \mathrm{~N}$, respectively. In comparison with CS, the main force $F_{z}$ and radial thrust force $F y$ of the TCS circular saw blade were decreased by about $12 \%$ and $7 \%$, respectively.

The variation of main sawing force $F z$ with feed rate was showed in Fig. 7. For the sawing speed of $50 \mathrm{~m} / \mathrm{min}$, the main sawing force $F z$ of CS circular saw blade was increased from $80 \mathrm{~N}$ to $115 \mathrm{~N}$ with the increase of feed rate from $0.4 \mathrm{~mm} / \mathrm{r}$ to $1.2 \mathrm{~mm} / \mathrm{r}$. For TCS circular saw blade, the main sawing force $F z$ was decreased by about $8 \sim 12 \%$ compared with CS circular saw blade with the increase of feed rate. For the sawing speed of $100 \mathrm{~m} / \mathrm{min}$, the range of main sawing force $F z$ value was wider than the sawing speed of $50 \mathrm{~m} / \mathrm{min}$ from about $83 \mathrm{~N}$ to $130 \mathrm{~N}$. The main sawing force $F z$ of TCS circular saw blade was reduced about $5 \sim 7 \%$ in comparison with CS with the increase of feed rate. For the sawing speed of $150 \mathrm{~m} / \mathrm{min}$, the range of $F z$ (from $86 \mathrm{~N}$ to $161 \mathrm{~N}$ ) was the largest with different feed rate, and the value of $F z$ was close to each other of CS and TCS circular saw blade. Compared to CS, the main sawing force $F z$ of TCS was reduced about $3 \sim 7 \%$.
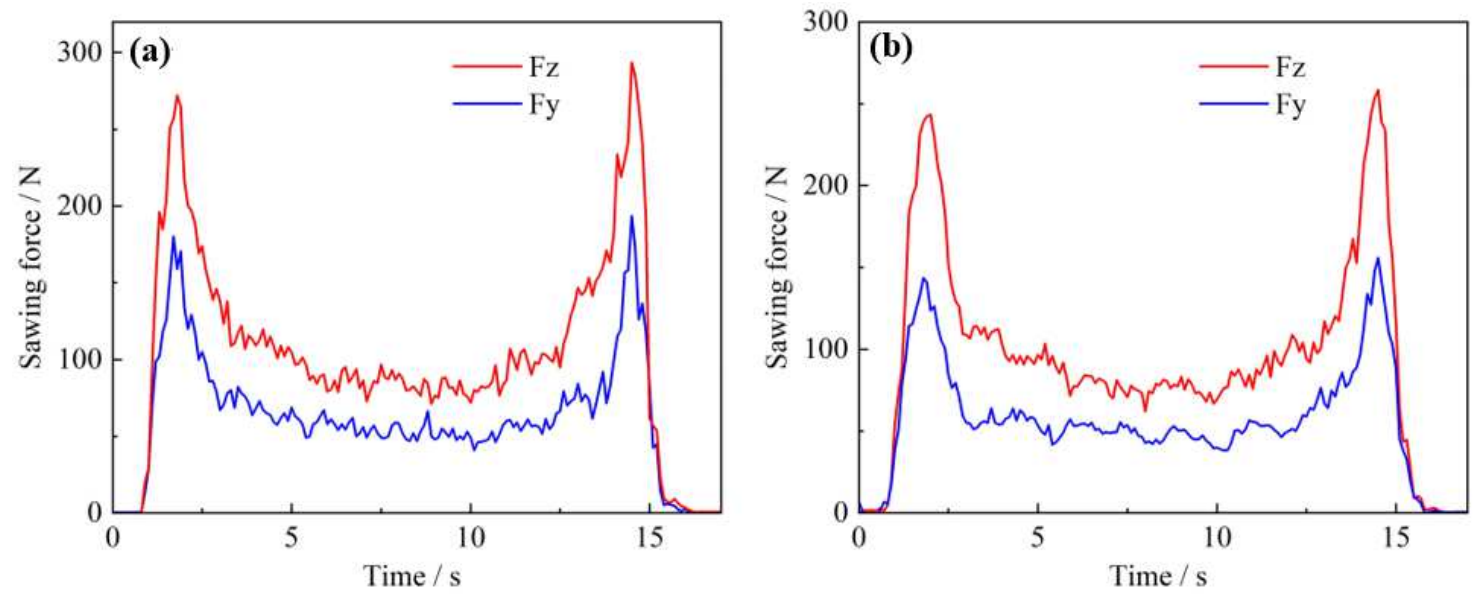

Fig. 6 Variation of sawing forces at sawing speed $50 \mathrm{~m} / \mathrm{min}$ and feed rate $0.8 \mathrm{~mm} / \mathrm{r}$ : (a) CS circular saw blade; (b) TCS circular saw blade. 

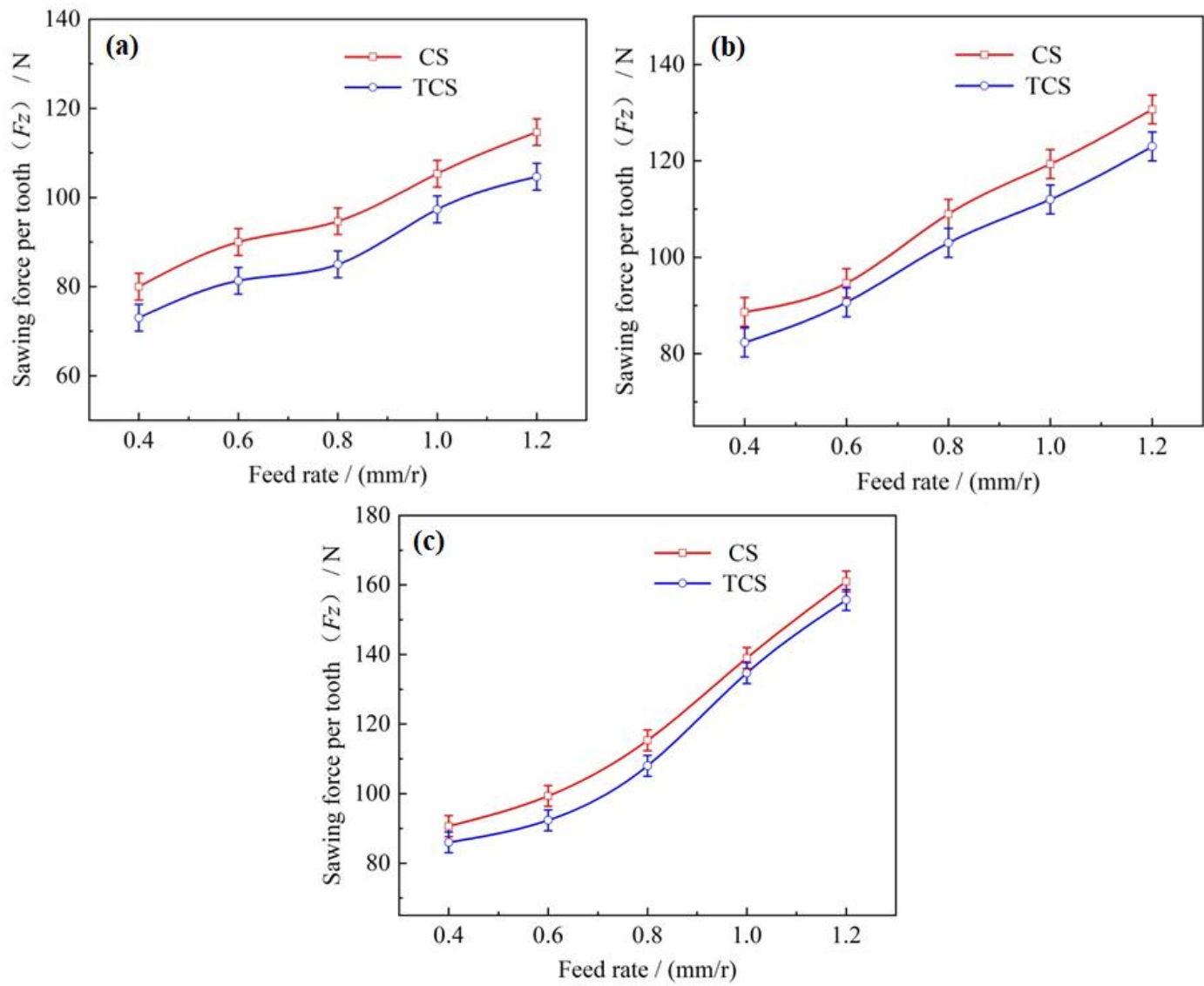

Fig. 7 The variation of main sawing force $F z$ with feed rate: (a) sawing speed $50 \mathrm{~m} / \mathrm{min}$; (b) sawing speed $100 \mathrm{~m} / \mathrm{min}$; (c)

sawing speed $150 \mathrm{~m} / \mathrm{min}$.

\subsection{Sawing temperature}

During the sawing process, a lot of energy would be involved for chip removal, which would generate considerable amounts of heat. In this work, the influence of sawing speed and feed rate on the sawing temperature for CS and TCS circular saw blade were evaluated under lubrication condition. Fig. 8 illustrated the sawing temperature of CS and TCS circular saw blade under the condition of sawing speed $100 \mathrm{~m} / \mathrm{min}$ and feed rate $1.2 \mathrm{~mm} / \mathrm{r}$. It can be seen that the temperature of the cutting position and the circumferential of the circular saw blade were higher. For TCS circular saw blade, the sawing temperature was decreased by about $6.8 \%$ in comparison with the CS circular saw blade.

The contour map of the sawing temperature of CS and TCS circular saw blade with different sawing 
speed and feed rate was exhibited in Fig. 9. For the sawing speed of 50, 100 and $150 \mathrm{~m} / \mathrm{min}$, the sawing temperature of CS was increased from about 109 to $196{ }^{\circ} \mathrm{C}, 120$ to $229^{\circ} \mathrm{C}$ and 137 to $320^{\circ} \mathrm{C}$, respectively with the increase of feed rate from 0.4 to $1.2 \mathrm{~mm} / \mathrm{r}$. For the TCS circular saw blade, the sawing temperature was decreased about $6 \sim 14 \%$ under different sawing speed and feed rate in contrast with that of the CS circular saw blade. The emulsified cutting fluids can penetrate into the tool-chip contact area through the micro textures resulted in better lubrication and cooling, and thereby reduced the cutting temperature.
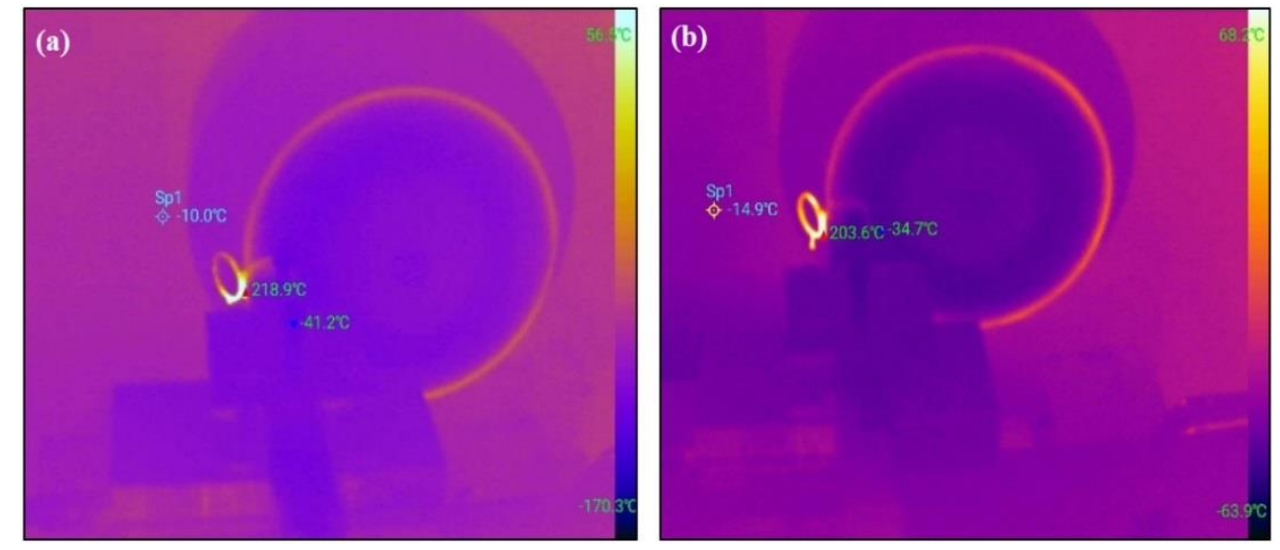

Fig. 8 The sawing temperature under the condition of sawing speed $100 \mathrm{~m} / \mathrm{min}$ and feed rate $1.2 \mathrm{~mm} / \mathrm{r}$ : (a) CS circular saw blade; (2) TCS circular saw blade.
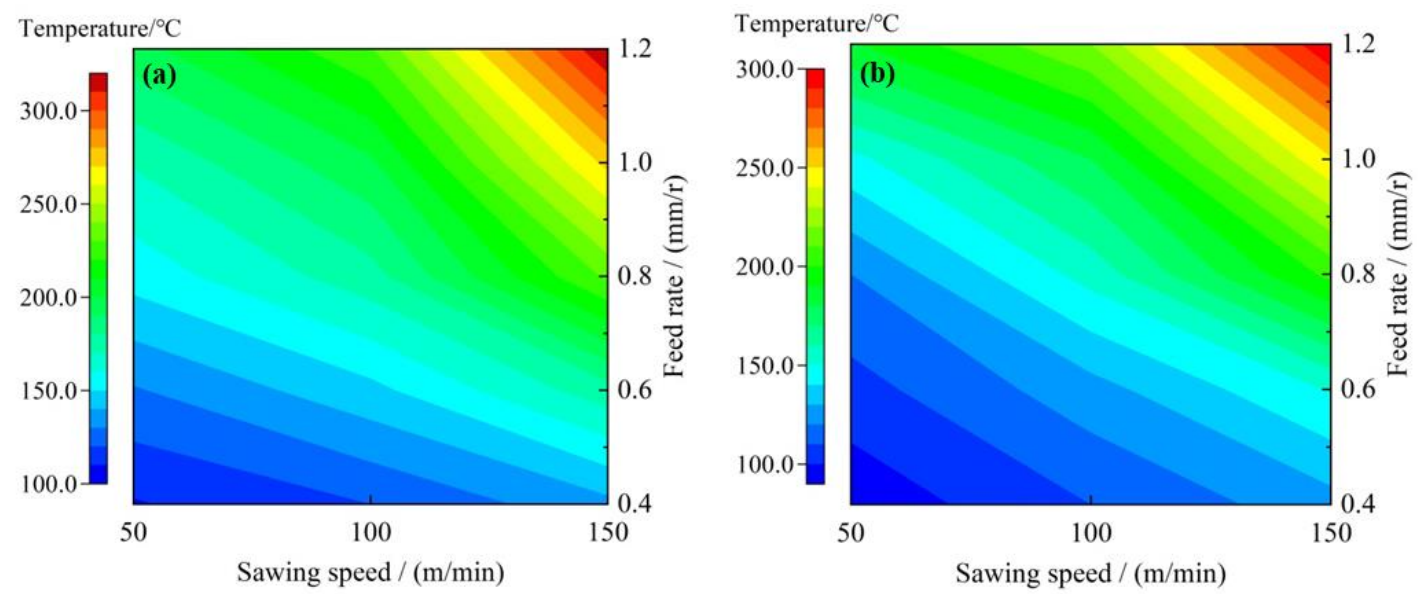

Fig. 9 The contour map of the sawing temperature with different sawing speed and feed rate: (a) CS circular saw blade; (b) 


\subsection{Machined surface roughness}

The machined surface roughness Ra of the workpiece was measured and presented in Fig. 10. An increase of feed rate and sawing speed lead to the increase of surface roughness Ra. The machined surface roughness Ra of the workpiece was range from about $1.7 \mu \mathrm{m}$ to $8.2 \mu \mathrm{m}$ under different sawing conditions. When the sawing speed was $50 \mathrm{~m} / \mathrm{min}$, the machined surface roughness Ra was increased from about 1.78 $\mu \mathrm{m}$ to $3.41 \mu \mathrm{m}$ with the increase of feed rate by CS circular saw blade. For TCS circular saw blade, the machined surface roughness was decreased about $1 \% \sim 5 \%$ in comparison with CS circular saw blade. When the sawing speed was $100 \mathrm{~m} / \mathrm{min}$, the machined surface roughness was increased from about 1.35 $\mu \mathrm{m}$ to $3.31 \mu \mathrm{m}$ with the increase of feed rate and reduced about $5 \% \sim 12 \%$ compared with CS circular saw blade. When the sawing speed was $150 \mathrm{~m} / \mathrm{min}$, the worn of CS and TCS circular saw blade were serious and the machined surface roughness changed greatly from about $3.31 \mu \mathrm{m}$ to $8.19 \mu \mathrm{m}$. For TCS circular saw blade, the machined surface roughness was reduced about $4 \% \sim 5 \%$ compared with CS circular saw blade.
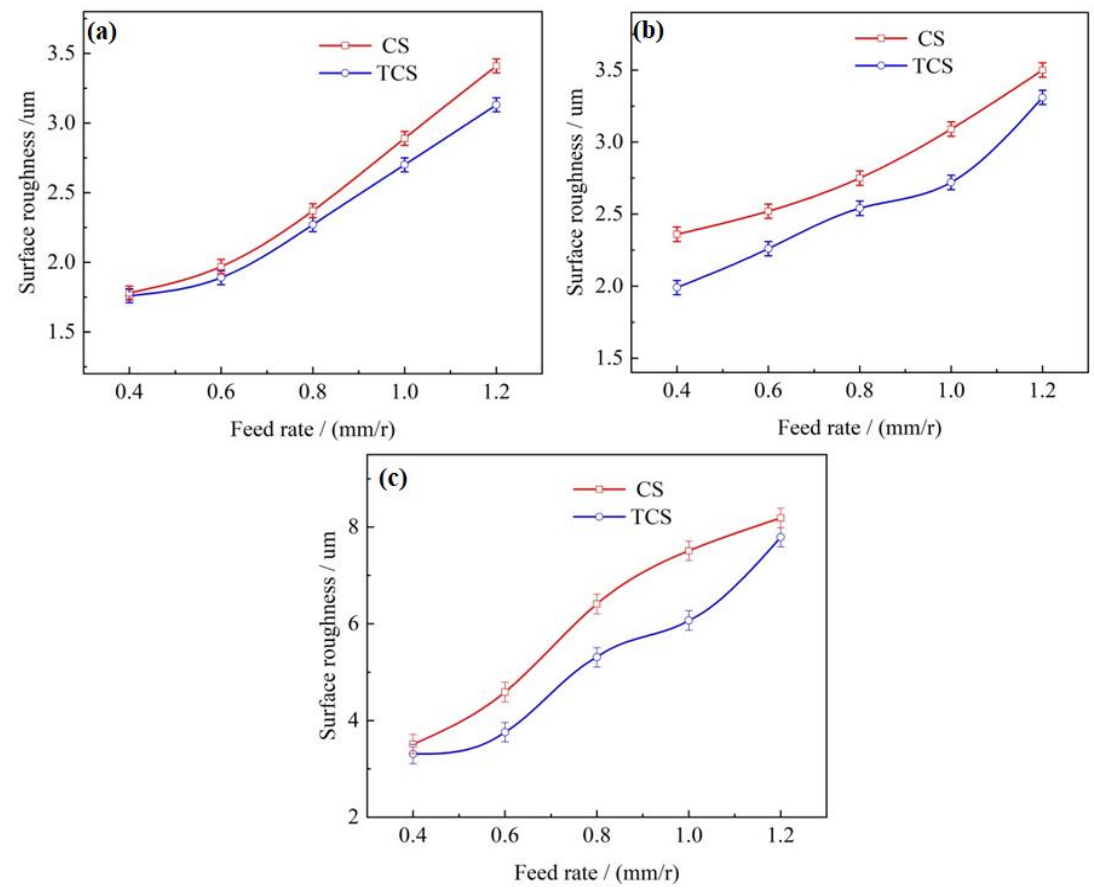

Fig. 10 The variation of machined surface roughness with feed rate: (a) sawing speed $50 \mathrm{~m} / \mathrm{min}$; (b) sawing speed $100 \mathrm{~m} / \mathrm{min}$; 


\subsection{Morphology of machined surface}

The machined surface roughness and burrs were important factors affected the quality of steel pipe machining. The morphology of machined surface by CS and TCS circular saw blade at feed rate $1.2 \mathrm{~mm} / \mathrm{r}$ and different sawing speed were showed in Fig. 11 and Fig. 12, respectively. For CS circular saw blade, some abrasive marks, burrs and adhesions were formed on the machined surface at the sawing speed 50 $\mathrm{m} / \mathrm{min}$ (Fig. 11(a) and (b)). When the sawing speed was $100 \mathrm{~m} / \mathrm{min}$, the height of burrs on the inner side machined surface of the steel pipe was higher (Fig. 11(c)). Fig. 11(d) showed the machined surface roughness was increased significantly, and a large number of adhesions and cracks were appeared.
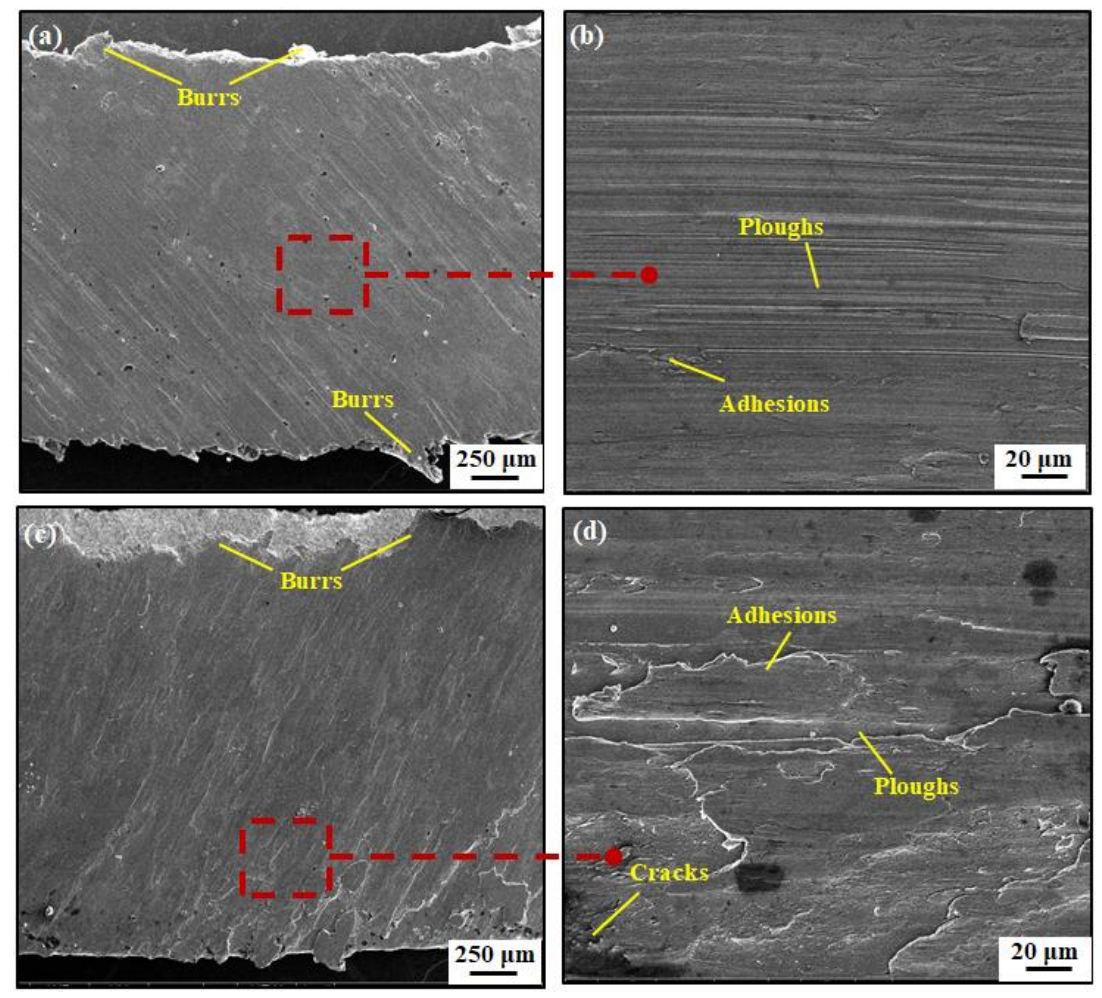

Fig. 11 The morphology of machined surface by CS circular saw blade at feed rate $1.2 \mathrm{~mm} / \mathrm{r}$ : (a), (b) sawing speed $50 \mathrm{~m} / \mathrm{min}$; (c), (d) sawing speed $100 \mathrm{~m} / \mathrm{min}$.

For TCS circular saw blade, the number and height of burrs on the inner side machined surface of the steel pipe were reduced compared with CS circular saw blade. When the sawing speed was $50 \mathrm{~m} / \mathrm{min}$, some lamellar adhesions and ploughs appeared on the machined surface, and the burrs mainly existed in the inner 
machined surface of the steel pipe (Fig. 12(a) and (b)). For the sawing speed $100 \mathrm{~m} / \mathrm{min}$, the height of the burrs and the surface roughness were higher in contrast to the low sawing speed $(50 \mathrm{~m} / \mathrm{min})$, in addition, some cracks and ploughs exposed on the machined surface (Fig. 12(c) and (d)).
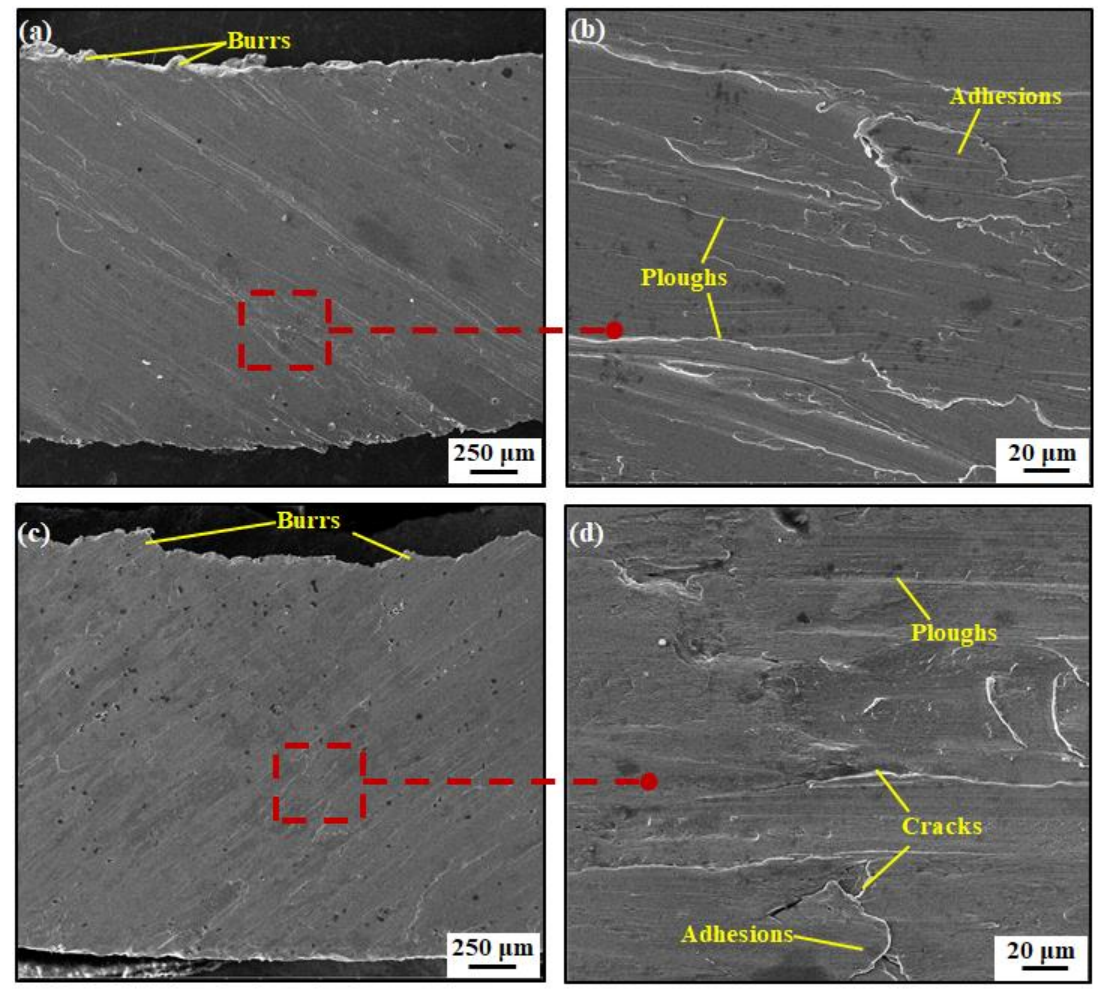

Fig. 12 The morphology of machined surface by TCS circular saw blade at feed rate $1.2 \mathrm{~mm} / \mathrm{r}$ : (a), (b) sawing speed 50 $\mathrm{m} / \mathrm{min}$; (c), (d) sawing speed $100 \mathrm{~m} / \mathrm{min}$.

\subsection{Cutter worn characteristics}

The worn of the tool surface was mainly caused by the physical and chemical reaction between the chip material and the circular saw blade material. Fig. 13 exhibited the worn surface morphologies and corresponding EDS maps of the CS circular saw blade after sawing 15 times 304 stainless steel pipes with cutting fluid lubrication at different sawing speed $(50-150 \mathrm{~m} / \mathrm{min})$ and feed rate $(0.4-1.2 \mathrm{~mm} / \mathrm{r})$. The morphologies results suggested that many lamellar chips and wear debris adhesive to the worn surface of the CS circular saw blade. The worn of the sawtooth sawing edge was seriously, and the corners on the both sides had been worn out, and showed an arc shape as shown in Fig. 13 (a) and (b). In addition, the chip was 
seriously piled up at the corners of the sawtooth, and deformed severely. Fig. 13 (c) illustrated the shape of the chip adhesive on the sawtooth, it can be revealed that the force, extrusion and deformation of the workpiece material removal in the sawing process. The corresponding EDS maps of the sawtooth worn surface were shown in Fig. 13 (d-g). It can be seen that the whole sawtooth worn surface was covered with $\mathrm{Ni}$ element because the workpiece material adhesive to the surface during the sawing process. The material of circular saw blade and workpiece didn't contain Na element, however, the emulsified cutting fluid contained Na element. Fig. 13 (f) illustrated $\mathrm{Na}$ element was also observed to the sawing zone and played a lubrication and cooling effect during the sawing progress. In addition, oxidation occurred on the sawtooth worn surface (Fig. 13 (g)). As mentioned above, although the emulsified cutting fluid can play a lubrication and cooling role, the severe adhesion and oxidation wear occurred on the sawtooth worn surface.

The worn surface morphologies and corresponding EDS maps of the TCS circular saw blade after sawing 15 times 304 stainless steel pipes with cutting fluid lubrication at different sawing speed and feed rate were shown in Fig. 14. A small amount of worn and adhesion of TCS sawtooth surface were showed in Fig. 14 (a) in comparison with CS circular saw blade. Micro textures still existed on the sawtooth surface and some adhesions appeared on the side of the micro textures away from the edge (Fig. 14 (b)). The results showed that the cutting fluid can penetrate into the sawtooth-chip friction contact zone through the micro textures, thus reducing the sawing temperature and adhesion of the worn surface. Fig. 14 (c) illustrated the worn and adhesion of the sawtooth corners on the both side were reduced compared to CS. The corresponding EDS maps of the TCS circular saw blade worn surface were observed and showed in Fig. 14 (d-g). The results showed that the adhesion of the workpiece material also covered whole sawtooth surface, and the serious adhesion occurred on the corners of the sawtooth edge. The distribution of the $\mathrm{Na}$ element was observed in Fig.14 (f) further demonstrated that the cutting fluid successfully penetrated into the sawtooth-chip frictional contact zone during the sawing process. Furthermore, Fig.14 (g) illustrated that 
the oxidative worn occurred in the contact area of the sawtooth surface.


Fig. 13 The worn surface morphologies and corresponding EDS maps of the CS circular saw blade: (a)-(c) SEM images of the worn surface; (d) Fe element; (e) Ni element; (d) Na element; (d) O element.
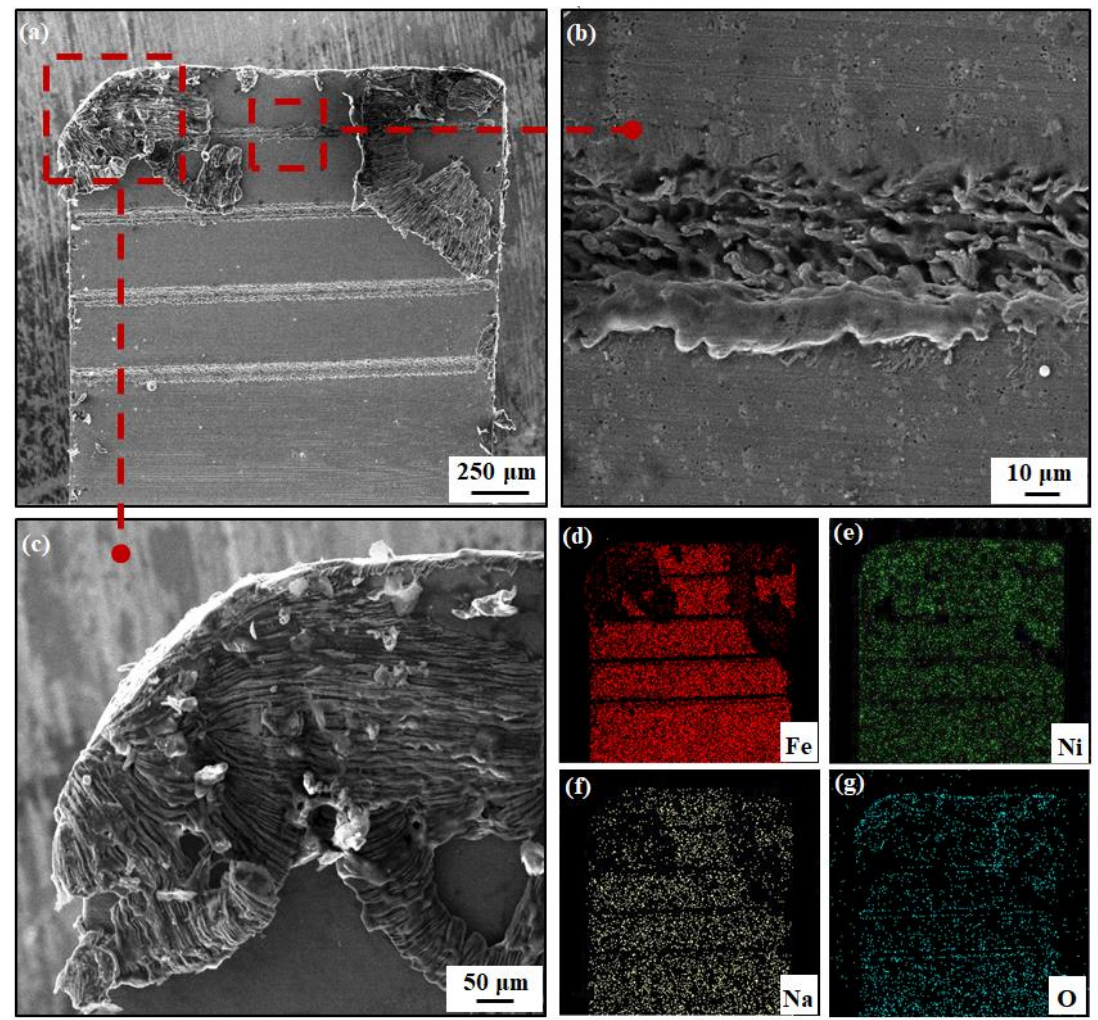

Fig. 14 The worn surface morphologies and corresponding EDS maps of the TCS circular saw blade: (a)-(c) SEM images of the worn surface; (d) Fe element; (e) Ni element; (d) Na element; (d) O element. 


\section{Discussion}

The friction and lubricating behavior of the tool-chip interface would affect tool life and machined surface quality. In this work, the micro textures were fabricated on the tool-chip contact interface, and the performance of micro textured circular saw blade (TCS) in sawing 304 stainless steel pipes under different sawing speed and feed rate with fluid lubrication. The friction force $\left(F_{f}\right)$ can be calculated from the following equation [29]:

$F_{f}=a_{w} l_{f} \tau_{c}$

Where $a_{w}$ was the cut width, $l_{f}$ was the tool-chip contact length, and $\tau_{c}$ was the average shear strength at the tool-chip interface. The resultant force $F_{r}$, main sawing force $F_{z}$ and thrust force $F_{y}$ of each tooth were obtained from the following equations:

$$
\begin{aligned}
& F_{r}=F_{f} / \sin \beta=\frac{a_{w} l_{f} \tau_{c}}{\sin \beta} \\
& F_{\mathrm{z}}=F_{r} \cos \left(\beta-\gamma_{0}\right)=\frac{a_{w} l_{f} \tau_{c} \cos \left(\beta-\gamma_{0}\right)}{\sin \beta} \\
& F_{\mathrm{y}}=F_{r} \sin \left(\beta-\gamma_{0}\right)=\frac{a_{w} l_{f} \tau_{c} \sin \left(\beta-\gamma_{0}\right)}{\sin \beta}
\end{aligned}
$$

Where $\beta$ was the friction angle and $\gamma_{o}$ was the rake angle.

Eqs. (6), (7) and (8) indicated that $F_{r}, F_{z}$, and $F_{y}$ were linearly related to the cut width $a_{w}$, tool-chip contact length $l_{f}$ and average shear strength at the sawtooth-chip interface $\tau_{c}$. As shown in Fig. 6 and 7, the sawing force (main sawing force $F_{z}$ and thrust force $F_{y}$ ) of TCS circular saw blade was reduced compared to CS circular saw blade. It can be attributed two mainly aspects: on the one hand, the tool-chip contact length $l_{f}$ (Fig. 14) of the TCS circular saw blade was decreased in comparison with CS, which was mainly due to the fabrication of micro textures on the sawtooth surface $[22,24,30]$. And the effective tool-chip contact length $l_{t}$ of TCS circular saw blade can be calculated as: 
$l_{t}=l_{f}-n d_{t}$

where $d_{t}$ was the width of the micro texture and $n$ was the texture quantity in the effective contact zone. On the other hand, in the sawing process of circular saw blade (CS), due to the high pressure and temperature of the sawtooth-chip interface, only little cutting fluid penetrated into the friction and contact zone [22,31]. However, the cutting fluid penetrated into the interface of sawtooth and chip through micro textures and formed a stable lubrication film. Thus average shear strength at the sawtooth-chip interface $\tau_{c}$ of TCS circular saw blade was reduced in comparison with CS. As mentioned above, the sawing force of TCS circular saw blade was reduced on account of the combined effect of micro textures under the lubrication condition of cutting fluid.

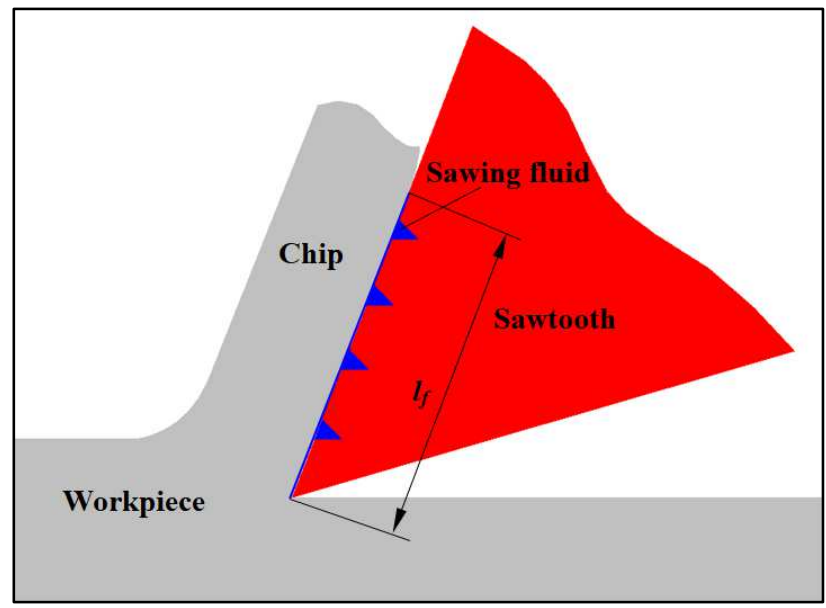

Fig. 15 The distribution schematic diagram of cutting fluid on the sawtooth-chip interface.

Furthermore, the micro textures made the cutting fluid penetrated into the sawtooth-chip interface easier and reduced the effective contact zone, which will effective reduced the sawing force, sawing temperature, machined surface roughness and decreased the sawtooth wear. The pressure in the micro textures was lower than the external pressure and the cutting fluid actively flowed into micro textures, which mainly due to the chip flowed on the sawtooth surface with high speed. Then, the cutting fluid 
flowed out from the micro-texture, and formed a stable lubrication film on the sawtooth-chip interface as shown in Fig. 15. In consequence, the macro textured circular saw blade (TCS) exhibited a better cutting performance in comparison with traditional circular saw blade (CS). In addition, Fig. 13 and 14 illustrated the wear and adhesion of TCS circular saw blade after sawing 304 stainless steel pipes 15 times were relatively reduced compared to CS.

The cutting performance of micro textured circular saw blade was improved effectively, owing to decreasing the tool-chip contact length, sawing force and sawing temperature, reducing the wear and adhesion of the sawtooth surface, and improving the quality of the machined surface. However, the worn on the corners of the sawtooth edge was seriously, and the sustainability of high speed steel sawtooth need to be improved.

\section{Conclusions}

In this paper, linear micro textures that parallel to the sawtooth edge were fabricated on the surface of the high speed steel W6Mo5Cr4V2 circular saw blade. Sawing 304 stainless steel pipes tests were carried out with the micro textured circular saw blade (TCS) under the lubrication condition. The following conclusions can be obtained:

(1) The largest sawing arc length and sawing force were occurred on the circular saw blade sawing outward from the inner wall. Then, the second largest sawing arc length and force appeared on the circular saw blade first contact with the inner wall. When the circular saw blade was sawing to middle position of the pipes, the sawing arc length and sawing force were smaller and more stable.

(2) In the sawing process, micro textured circular saw blade (TCS) showed better cutting performance in comparison with traditional circular saw blade (CS) in terms of (i) reduced cutting forces and cutting 
temperatures, (ii) improved the quality of machined surface and decreased the number of burrs, (iii) reduced the wear and adhesion of sawtooth surface.

(3) The coupling effect mechanisms were found, on the one hand, the effective sawtooth-chip contact length was reduced due to the micro textures fabricated on the sawtooth surface, on the other hand, cutting fluid can be better penetrated into the micro textures and formed stable lubrication film in sawtooth-chip contact interface.

\section{Ethical approval}

The authors declare that this manuscript was not submitted to more than one journal for simultaneous consideration. Also, the submitted work is original and not have been published elsewhere in any form or language.

\section{Consent to participate and publish}

The authors declare that they participated in this paper willingly and the authors declare to consent to the publication of this paper.

\section{Authors Contributions}

Yang Lu: Formal analysis, Methodology, Data curation, Writing original draft. Jianxin Deng: Conceptualization, Supervision. Qinghao Sun: Supervision. Dongliang Ge: Investigation. Jiaxing Wu and Zhihui Zhang: Writing-review \& editing.

\section{Acknowledgements}

This work is supported by the Key Research and Development Projects of Shandong Province (2019TSLH0315) and the National Natural Science Foundation of China (51675311). 


\section{Conflict of interests}

The authors declare that there is no conflict of interests regarding the publication of this paper.

\section{Availability of data and materials}

The authors declare that data and materials are authentic and available.

\section{Reference}

1. Junz Wang J-J, Wu S-H, Lee R-S (2012) Chip fractal geometry and loading characteristics of sinusoidal multi-cutters in hack-sawing process. Int J Mach Tools Manuf 59:65-80. https://doi.org/https://doi.org/10.1016/j.ijmachtools.2012.01.005

2. Söderberg S, Åhman L, Svenzon M (1983) A metallurgical study of the wear of band-saw blades. Wear 85:11-27. https://doi.org/https://doi.org/10.1016/0043-1648(83)90332-0

3. Ko TJ, Kim HS (1999) Mechanistic cutting force model in band sawing. Int J Mach Tools Manuf 39:1185-1197. https://doi.org/https://doi.org/10.1016/S0890-6955(98)00087-X

4. Nishio S, Marui E (1996) Effects of slots on the lateral vibration of a circular saw blade. Int J Mach Tools Manuf 36:771-787. https://doi.org/https://doi.org/10.1016/0890-6955(95)00088-7

5. Lewis DB, Bradbury SR, Sarwar M (1996) The effect of substrate surface preparation on the wear and failure modes of TiN coated high speed steel circular saw blades. Wear 197:82-88. https://doi.org/https://doi.org/10.1016/0043-1648(95)06835-X

6. Chang WT, Chen LC (2016) Design and experimental evaluation of a circular saw blade with self-clamped cutting inserts. Int J Adv Manuf Technol 83:365-379. https://doi.org/10.1007/s00170-015-7563-7

7. Bradbury SR, Lewis DB (2000) Comparison of the performance and wear characteristics of high-speed steel circular 
saw blades machining Nimonic PK31, AISI O1 Tool Steel, Inconel 600L, and AISI 1018 Carbon Steel. J Mater Sci 35:1511-1524. https://doi.org/10.1023/A:1004749400522

8. Chang WT, Su CH, Guo DX, et al (2013) Automated optical inspection for the runout tolerance of circular saw blades. Int J Adv Manuf Technol 66:565-582. https://doi.org/10.1007/s00170-012-4350-6

9. Beljo-Lučić R, Goglia V (2001) Some possibilities for reducing circular saw idling noise. J Wood Sci 47:389-393. https://doi.org/10.1007/BF00766791

10. Alam MT, Kinoshita N, Tanaka C, Yoshinobu M (2002) Circular saw lateral stability by optimization of feed speed. Holz als Roh - und Werkst 60:207-209. https://doi.org/10.1007/s00107-002-0286-0

11. Nasir V, Mohammadpanah A, Cool J (2020) The effect of rotation speed on the power consumption and cutting accuracy of guided circular saw: Experimental measurement and analysis of saw critical and flutter speeds. Wood Mater Sci Eng 15:140-146. https://doi.org/10.1080/17480272.2018.1508167

12. Vladescu S-C, Olver A V, Pegg IG, Reddyhoff T (2015) The effects of surface texture in reciprocating contacts An experimental study. Tribol Int 82:28-42. https://doi.org/https://doi.org/10.1016/j.triboint.2014.09.015

13. Vlădescu S-C, Olver A V, Pegg IG, Reddyhoff T (2016) Combined friction and wear reduction in a reciprocating $\begin{array}{lllll}\text { contact } & \text { laser } & \text { surface } & \text { texturing. }\end{array}$ https://doi.org/https://doi.org/10.1016/j.wear.2016.03.035

14. Biboulet N, Bouassida H, Lubrecht AA (2015) Cross hatched texture influence on the load carrying capacity of oil control rings. Tribol Int 82:12-19. https://doi.org/https://doi.org/10.1016/j.triboint.2014.09.024

15. Segu DZ, Choi SG, Choi J hyouk, Kim SS (2013) The effect of multi-scale laser textured surface on lubrication regime. Appl Surf Sci 270:58-63. https://doi.org/https://doi.org/10.1016/j.apsusc.2012.12.068

16. Shen C, Khonsari MM (2016) The effect of laser machined pockets on the lubrication of piston ring prototypes. Tribol Int 101:273-283. https://doi.org/https://doi.org/10.1016/j.triboint.2016.04.009

17. Wang T, Huang W, Liu X, et al (2014) Experimental study of two-phase mechanical face Seals with laser surface 
texturing. Tribol Int 72:90-97. https://doi.org/https://doi.org/10.1016/j.triboint.2013.12.009

18. Tala-Ighil N, Fillon M (2015) Surface texturing effect comparative analysis in the hydrodynamic journal bearings.

Mech Ind 16:. https://doi.org/10.1051/meca/2015001

19. Ibatan T, Uddin MS, Chowdhury MAK (2015) Recent development on surface texturing in enhancing tribological performance of bearing sliders. Surf Coatings Technol 272:102-120. https://doi.org/https://doi.org/10.1016/j.surfcoat.2015.04.017

20. Duan R, Deng J, Lei S, et al (2019) Effect of derivative cutting on machining performance of micro textured tools. J Manuf Process 45:544-556. https://doi.org/https://doi.org/10.1016/j.jmapro.2019.07.037

21. Gropper D, Wang L, Harvey TJ (2016) Hydrodynamic lubrication of textured surfaces: A review of modeling techniques and key findings. Tribol Int 94:509-529. https://doi.org/https://doi.org/10.1016/j.triboint.2015.10.009

22. Ge D, Deng J, Duan R, et al (2019) Effect of micro-textures on cutting fluid lubrication of cemented carbide tools. Int J Adv Manuf Technol 103:3887-3899. https://doi.org/10.1007/s00170-019-03763-6

23. Kawasegi N, Sugimori H, Morimoto H, et al (2009) Development of cutting tools with microscale and nanoscale $\begin{array}{llllll}\text { textures } & \text { to } & \text { improve } & \text { Prictional }\end{array}$ https://doi.org/https://doi.org/10.1016/j.precisioneng.2008.07.005

24. Jianxin D, Ze W, Yunsong L, et al (2012) Performance of carbide tools with textured rake-face filled with solid lubricants in dry cutting processes. Int J Refract Met Hard Mater 30:164-172. https://doi.org/https://doi.org/10.1016/j.ijrmhm.2011.08.002

25. Neves D, Diniz AE, de Lima MSF (2006) Efficiency of the laser texturing on the adhesion of the coated twist drills. J Mater Process Technol 179:139-145. https://doi.org/https://doi.org/10.1016/j.jmatprotec.2006.03.068

26. Li Q, Yang S, Zhang Y, et al (2018) Evaluation of the machinability of titanium alloy using a micro-textured ball end milling cutter. Int J Adv Manuf Technol 98:2083-2092. https://doi.org/10.1007/s00170-018-2319-9

27. Zhou C, Guo X, Zhang K, et al (2019) The coupling effect of micro-groove textures and nanofluids on cutting 
performance of uncoated cemented carbide tools in milling Ti-6Al-4V. J Mater Process Technol 271:36-45.

https://doi.org/https://doi.org/10.1016/j.jmatprotec.2019.03.021

28. Ling TD, Liu P, Xiong S, et al (2013) Surface texturing of drill bits for adhesion reduction and tool life enhancement.

Tribol Lett 52:113-122. https://doi.org/10.1007/s11249-013-0198-7

29. Cheng RY (1992) Principle of metal cutting, first edn. China Machine Press, Beijing.

30. Song W, Wang S, Lu Y, Xia Z (2018) Tribological performance of microhole-textured carbide tool filled with CaF2.

Materials (Basel) 11:. https://doi.org/10.3390/ma11091643

31. Thepsonthi T, Hamdi M, Mitsui K (2009) Investigation into minimal-cutting-fluid application in high-speed milling

of hardened steel using carbide mills. Int J Mach Tools Manuf 49:156-162.

https://doi.org/https://doi.org/10.1016/j.ijmachtools.2008.09.007 
Figures
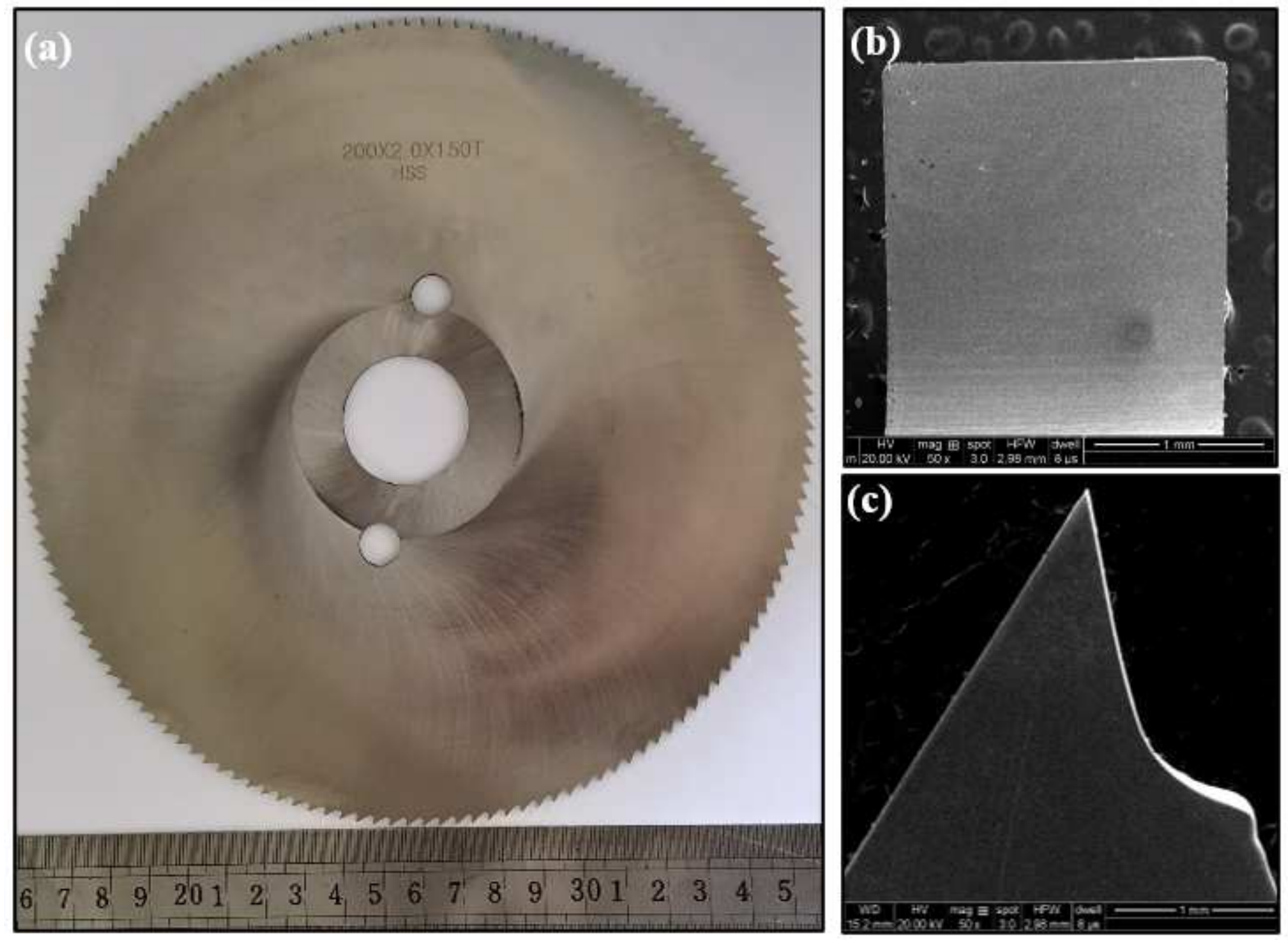

Figure 1

The photographs and SEM micrographs of a circular saw blade: (a) photographs of circular saw blade; (b) rake face of the sawtooth; (c) side morphology of the sawtooth. 
(a) cutting edge

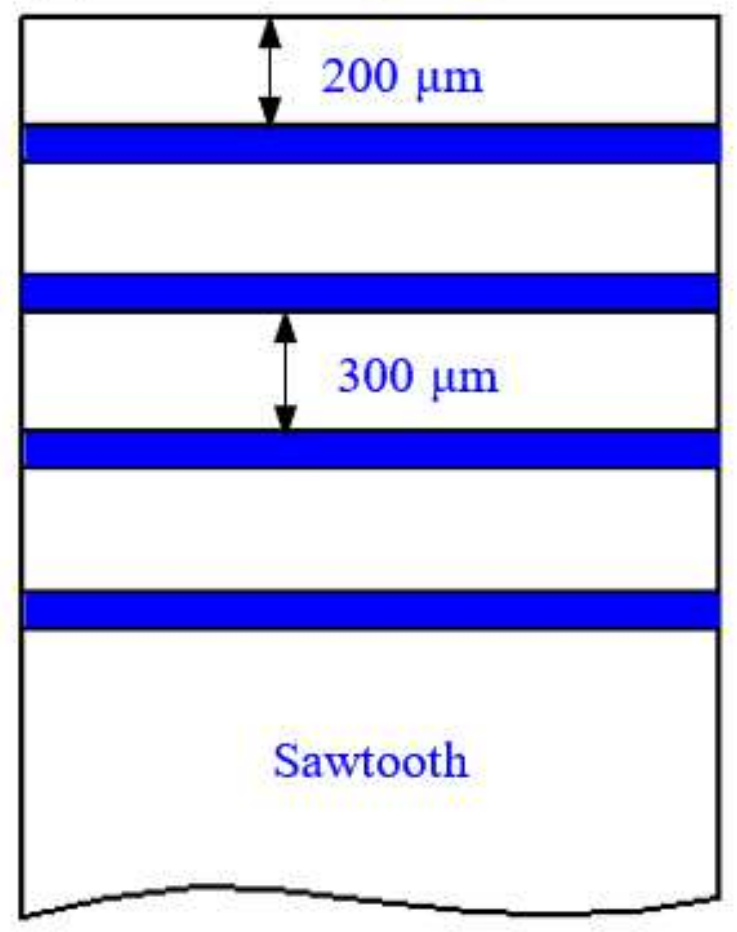

\section{(b)}

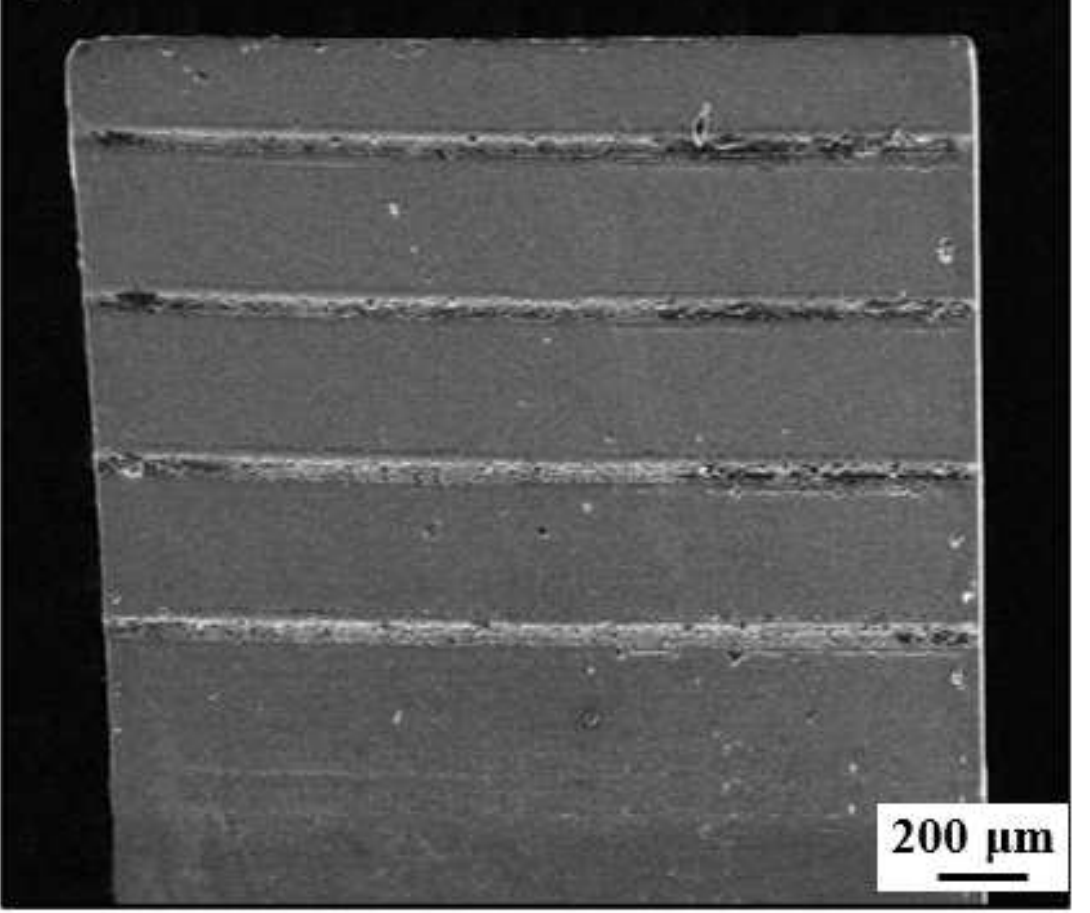

Figure 2

The sawtooth with micro textures: (a) Schematic diagram of the rake face micro textures; (b) SEM image of textured

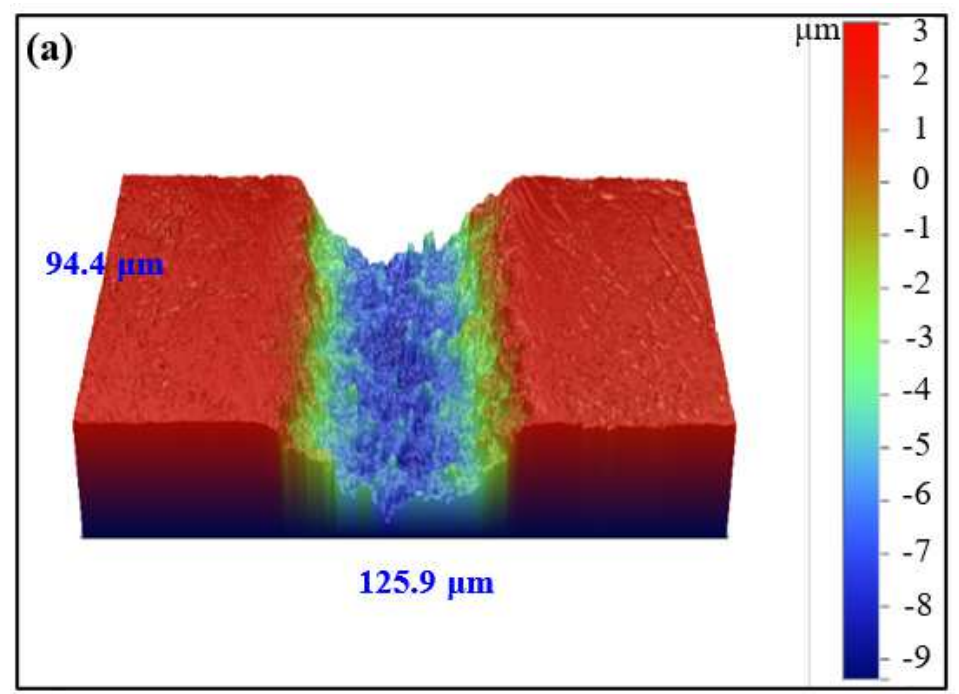

(b)

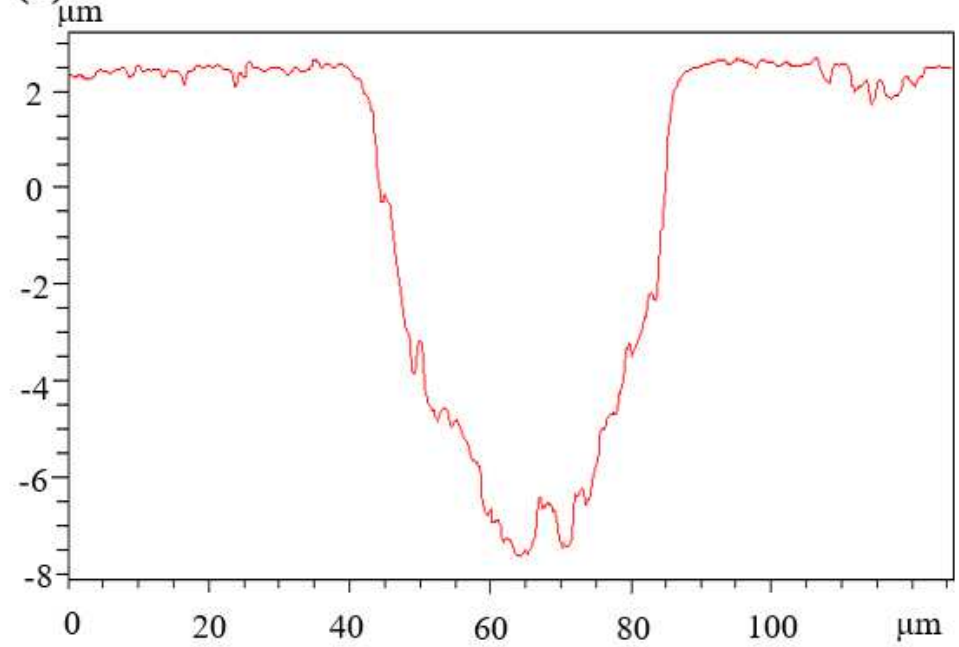

Figure 3

Surface morphology and geometry of the texture: (a) 3D optical micrographs of one micro-groove; (b) section profile of the micro-groove. 


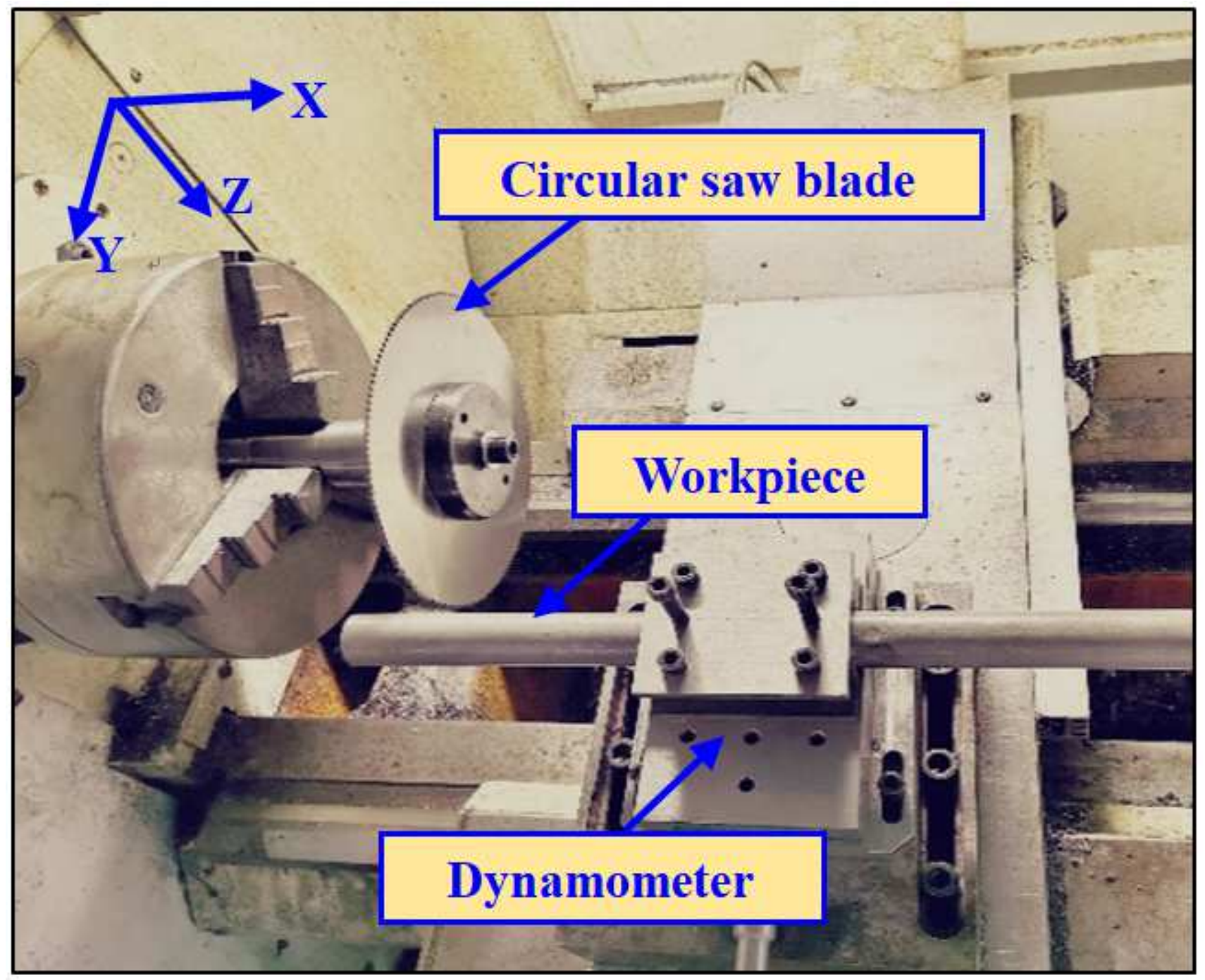

Figure 4

The photos of sawing 304 steel pipes tests.
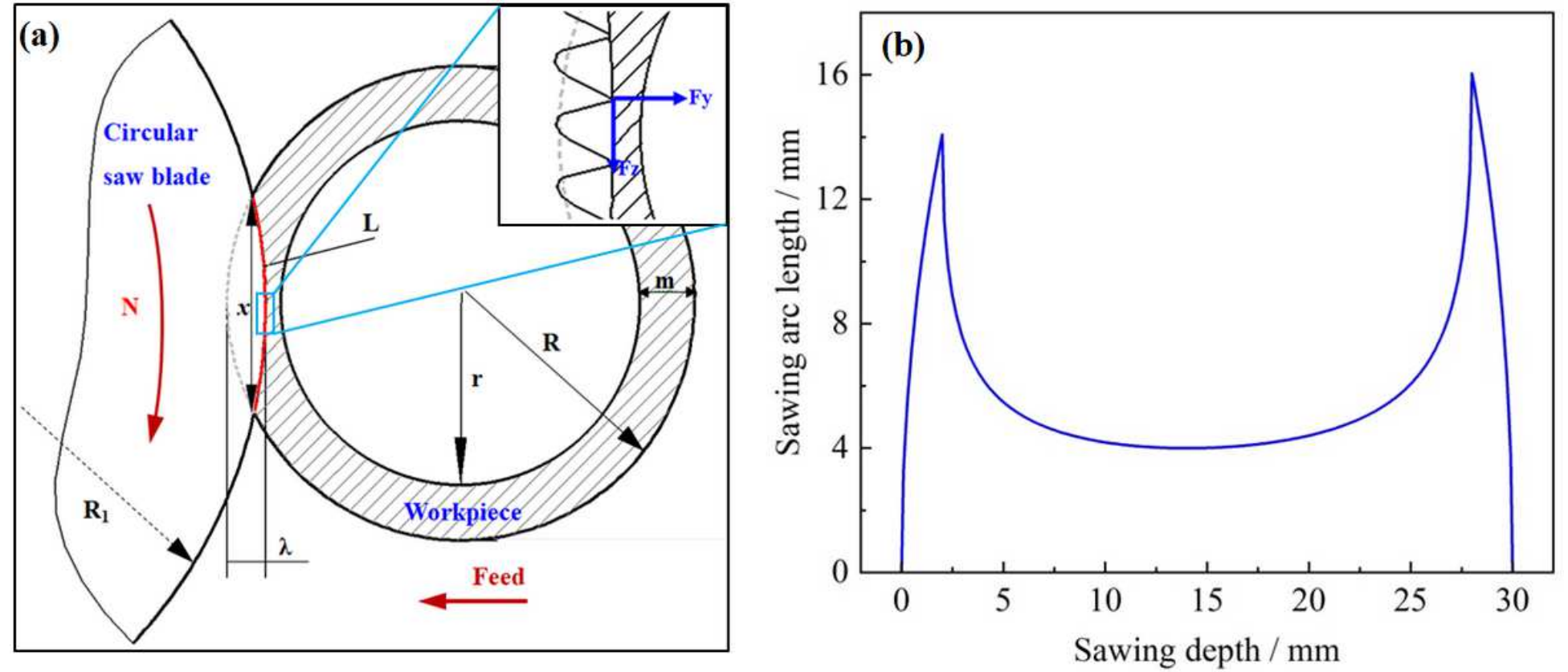
Figure 5

The schematic diagram of sawing force and variation of sawing arc length: (a) schematic diagram; (b) sawing arc length.
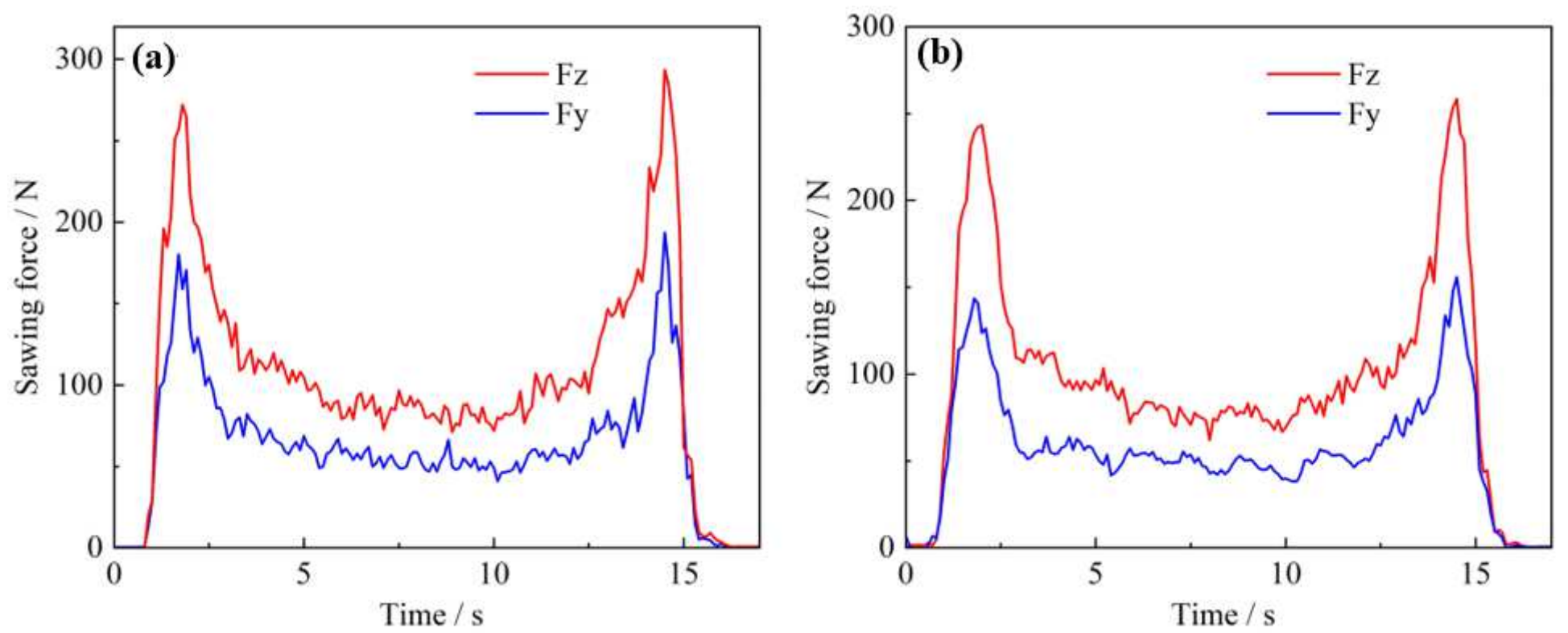

Figure 6

Variation of sawing forces at sawing speed $50 \mathrm{~m} / \mathrm{min}$ and feed rate $0.8 \mathrm{~mm} / \mathrm{r}$ : (a) CS circular saw blade; (b) TCS circular saw blade. 

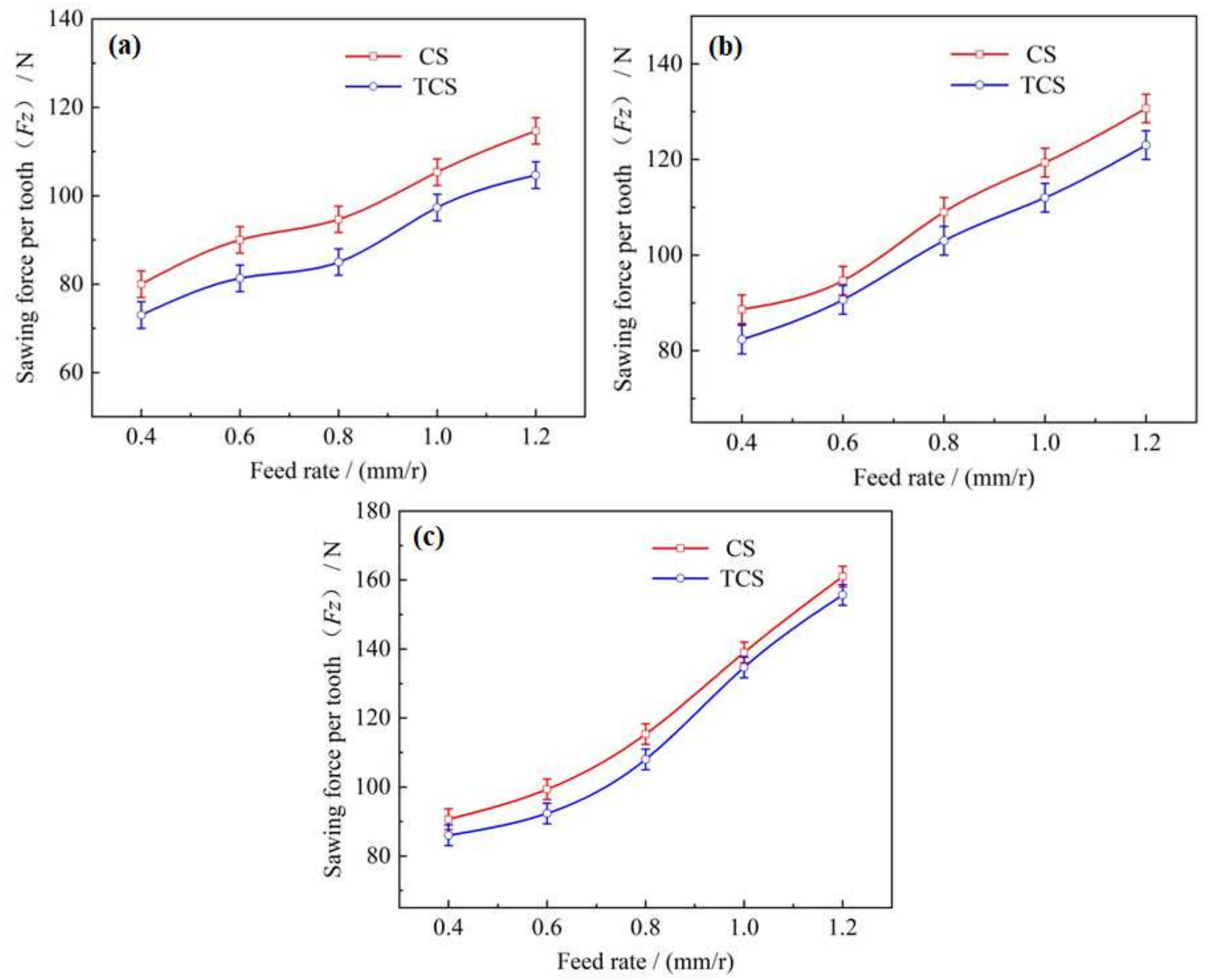

Figure 7

The variation of main sawing force Fz with feed rate: (a) sawing speed $50 \mathrm{~m} / \mathrm{min}$; (b) sawing speed 100 $\mathrm{m} / \mathrm{min}$; (c) sawing speed $150 \mathrm{~m} / \mathrm{min}$. 

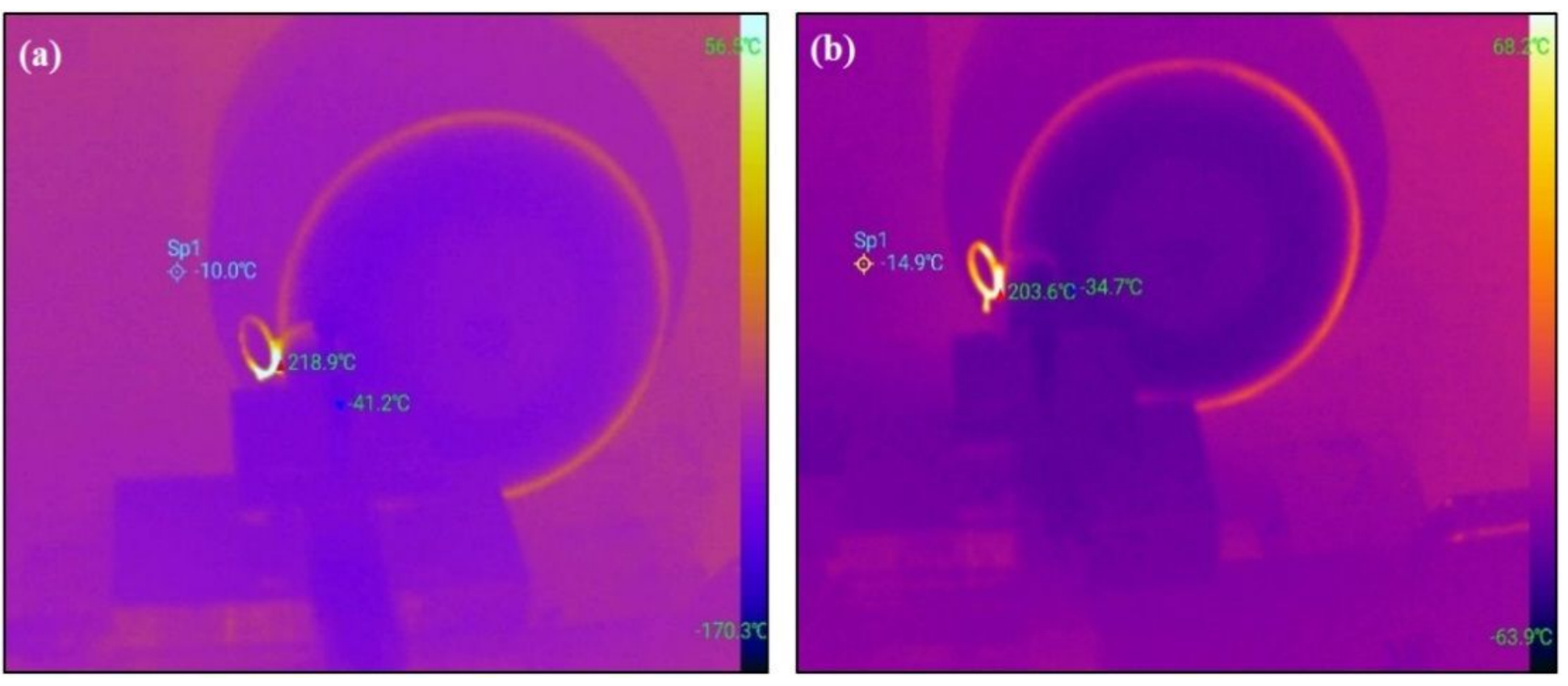

\section{Figure 8}

The sawing temperature under the condition of sawing speed $100 \mathrm{~m} / \mathrm{min}$ and feed rate $1.2 \mathrm{~mm} / \mathrm{r}$ : (a) CS circular saw blade; (2) TCS circular saw blade.
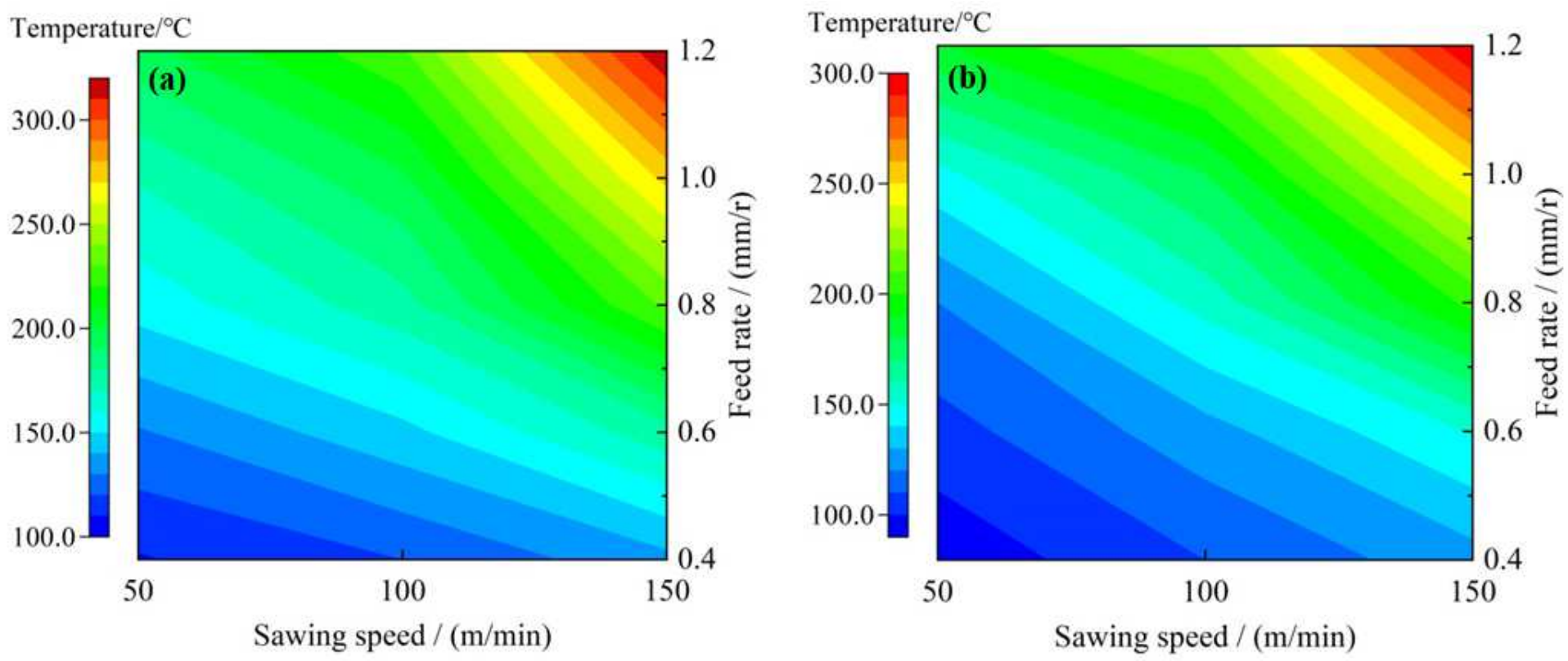

\section{Figure 9}

The contour map of the sawing temperature with different sawing speed and feed rate: (a) CS circular saw blade; (b) TCS circular saw blade. 

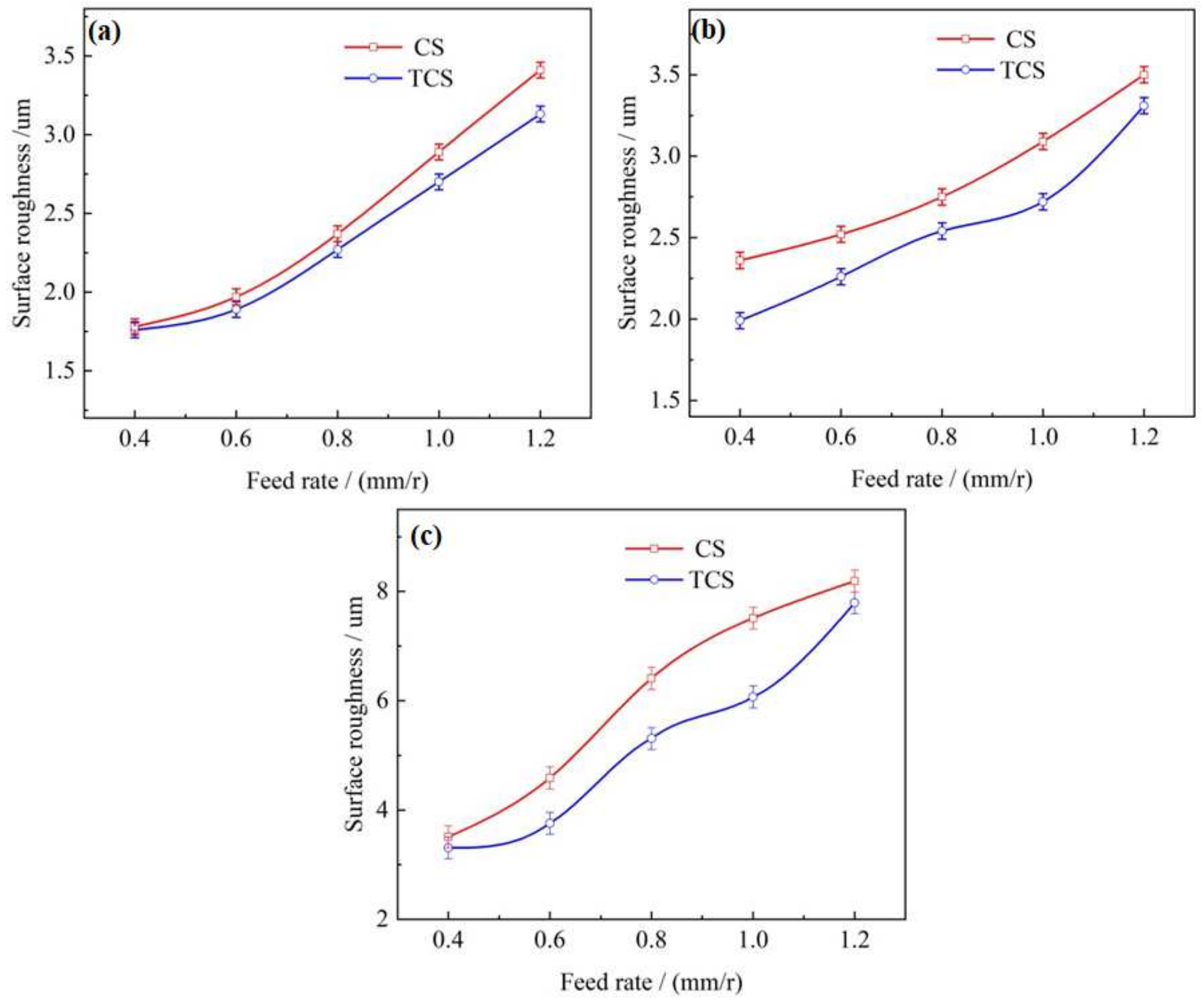

Figure 10

The variation of machined surface roughness with feed rate: (a) sawing speed $50 \mathrm{~m} / \mathrm{min}$; (b) sawing speed $100 \mathrm{~m} / \mathrm{min}$; (c) sawing speed $150 \mathrm{~m} / \mathrm{min}$. 

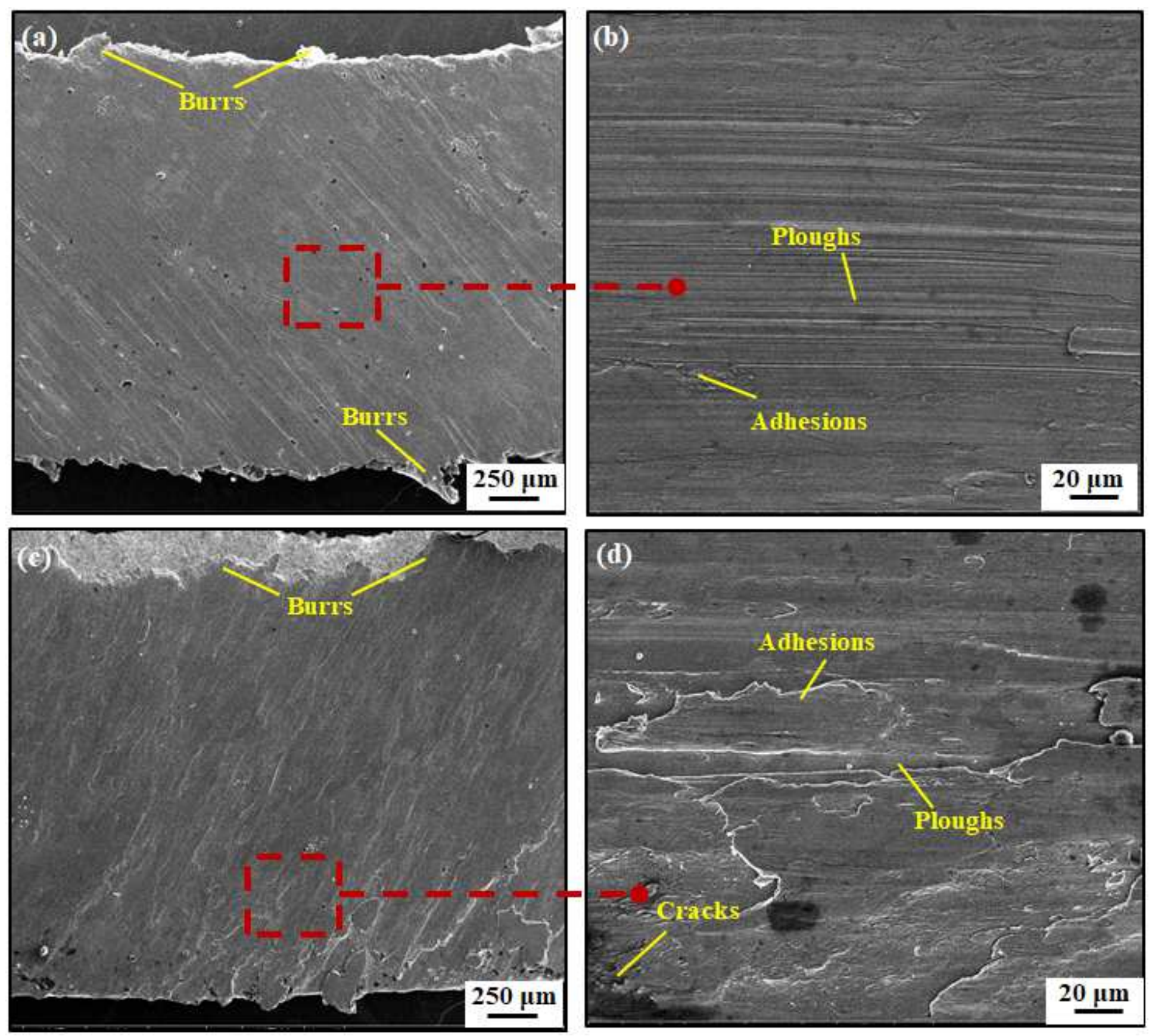

Figure 11

The morphology of machined surface by CS circular saw blade at feed rate $1.2 \mathrm{~mm} / \mathrm{r}$ : (a), (b) sawing speed $50 \mathrm{~m} / \mathrm{min}$; (c), (d) sawing speed $100 \mathrm{~m} / \mathrm{min}$. 

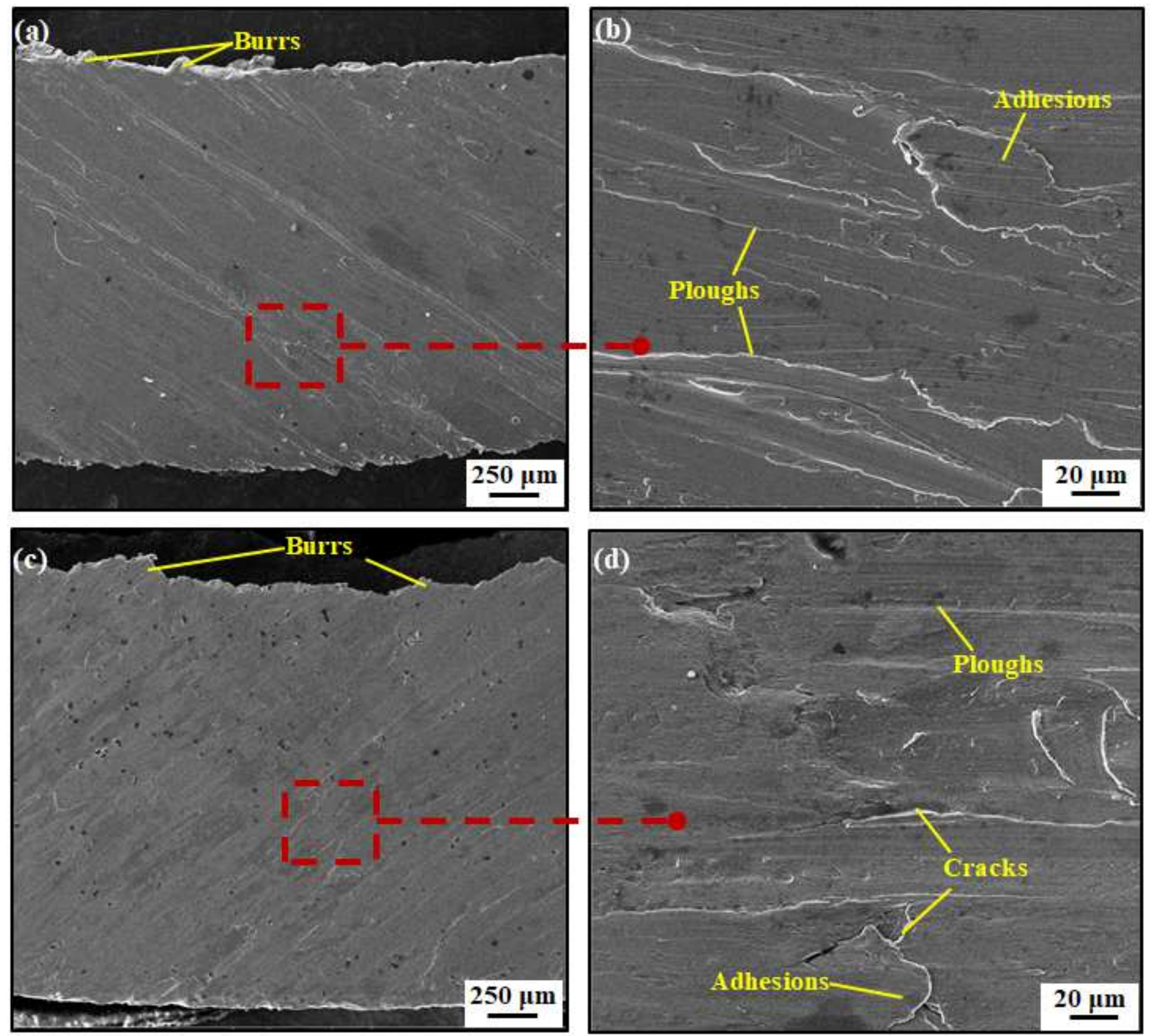

Figure 12

The morphology of machined surface by TCS circular saw blade at feed rate $1.2 \mathrm{~mm} / \mathrm{r}$ : (a), (b) sawing speed $50 \mathrm{~m} / \mathrm{min}$; (c), (d) sawing speed $100 \mathrm{~m} / \mathrm{min}$. 

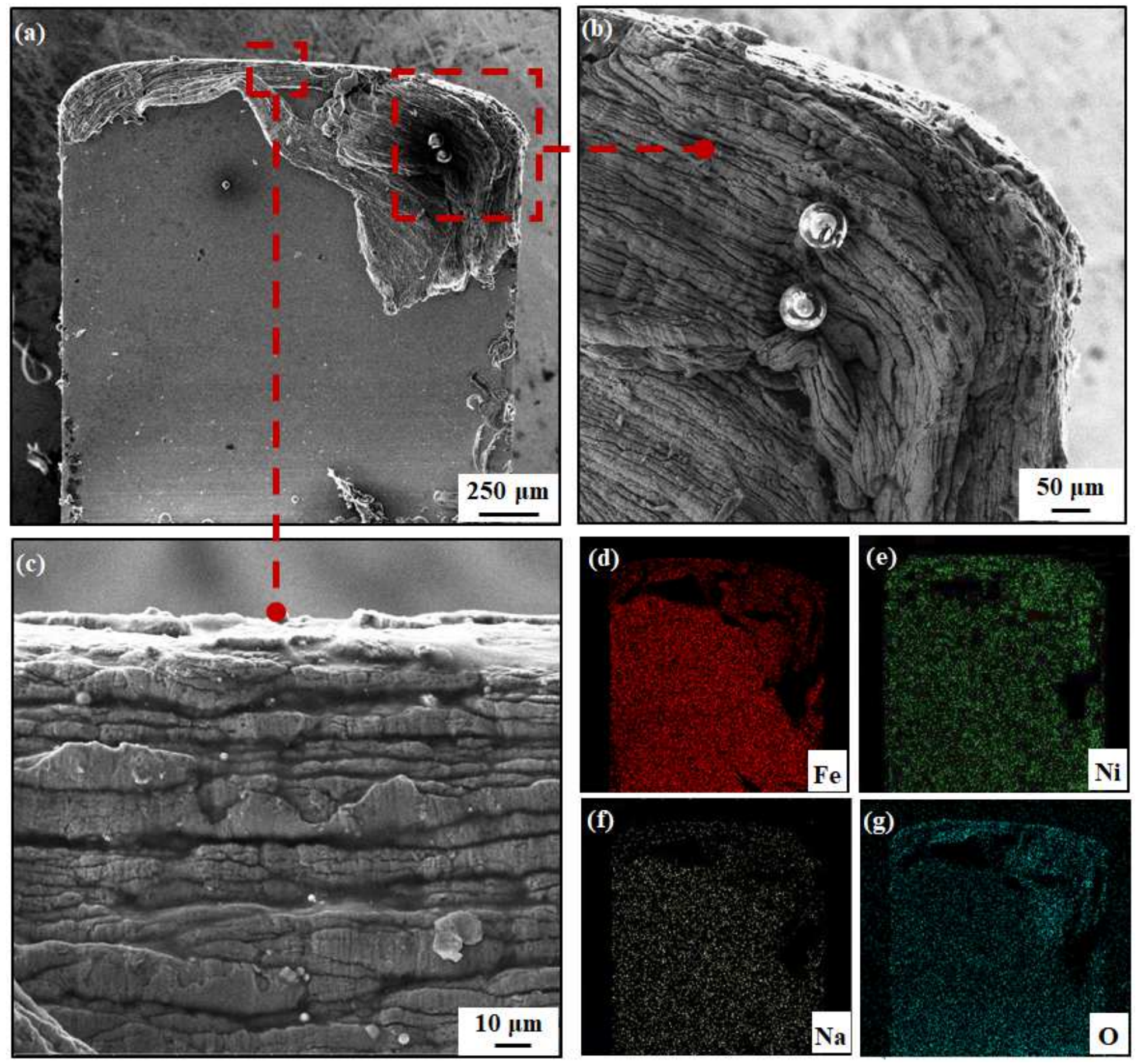

\section{Figure 13}

The worn surface morphologies and corresponding EDS maps of the CS circular saw blade: (a)-(c) SEM images of the worn surface; (d) Fe element; (e) Ni element; (d) Na element; (d) O element. Note: The designations employed and the presentation of the material on this map do not imply the expression of any opinion whatsoever on the part of Research Square concerning the legal status of any country, territory, city or area or of its authorities, or concerning the delimitation of its frontiers or boundaries. This map has been provided by the authors. 

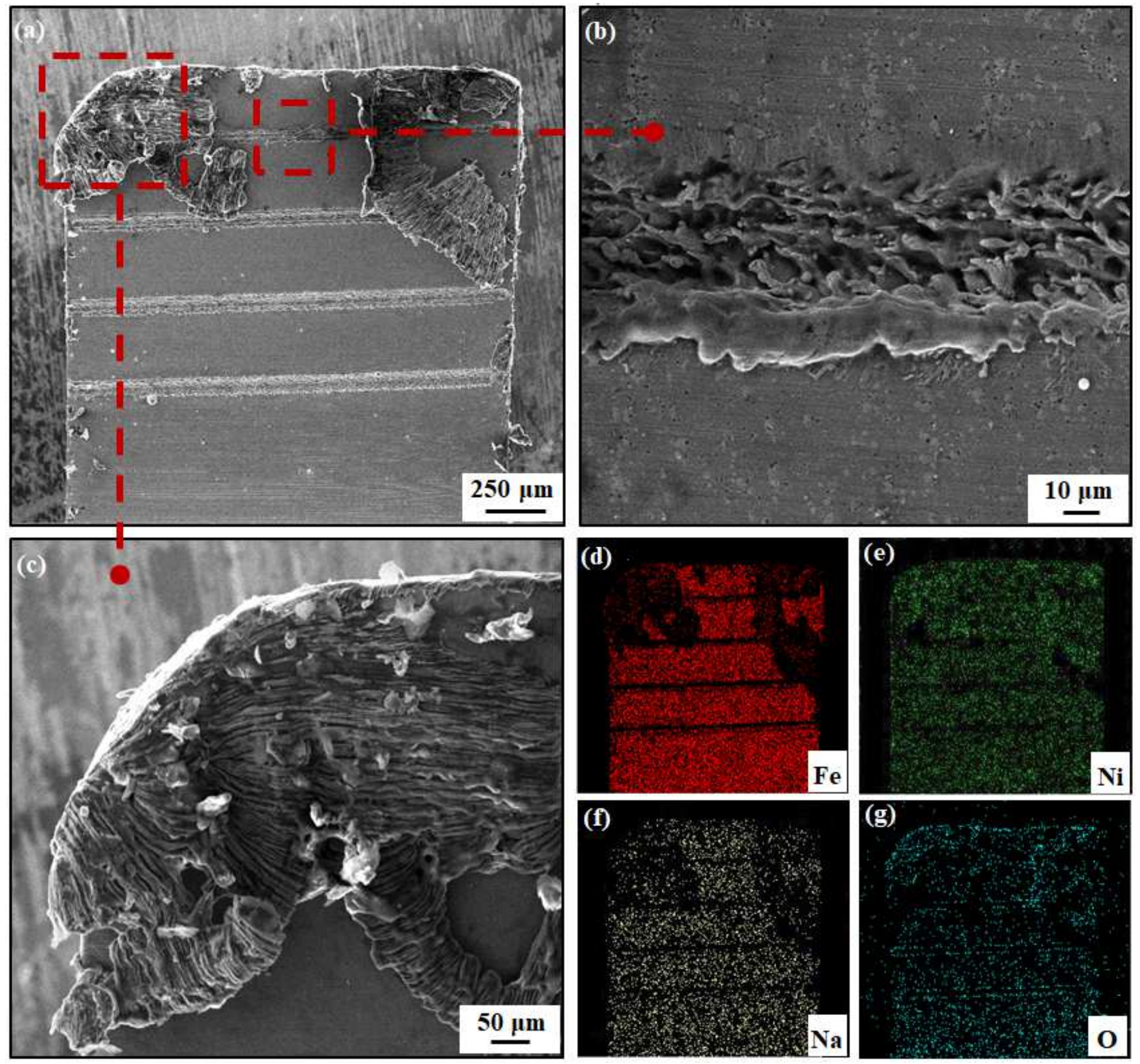

\section{Figure 14}

The worn surface morphologies and corresponding EDS maps of the TCS circular saw blade: (a)-(c) SEM images of the worn surface; (d) Fe element; (e) Ni element; (d) Na element; (d) O element. Note: The designations employed and the presentation of the material on this map do not imply the expression of any opinion whatsoever on the part of Research Square concerning the legal status of any country, territory, city or area or of its authorities, or concerning the delimitation of its frontiers or boundaries. This map has been provided by the authors. 


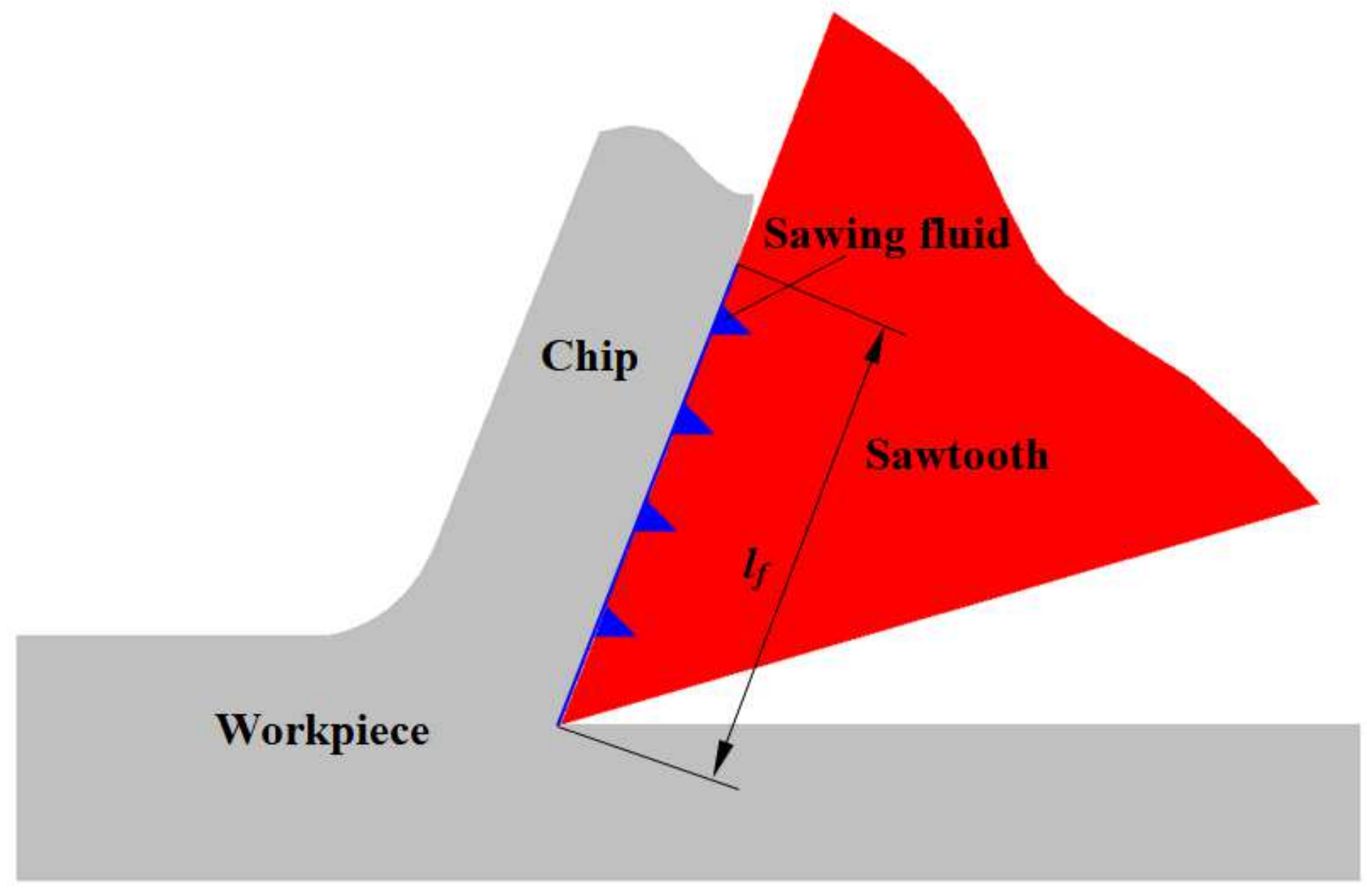

Figure 15

The distribution schematic diagram of cutting fluid on the sawtooth-chip interface. 